\title{
Behavioral and Neurochemical Phenotyping of Mice Incapable of Homer1a Induction
}

\author{
Michael C. Datko ${ }^{1}$, Jia-Hua Hü2, Melanie Williams ${ }^{3}$, Cindy M. Reyes ${ }^{1}$, Kevin D. Lominac', \\ Georg von Jonquieres ${ }^{4}$, Matthias Klugmann ${ }^{4}$, Paul F. Worley ${ }^{2}$ and \\ Karen K. Szumlinski ${ }^{1,3,5 *}$ \\ 1 Department of Psychological and Brain Sciences, University of California, Santa Barbara, Santa Barbara, CA, \\ United States, ${ }^{2}$ Department of Neuroscience, Johns Hopkins University School of Medicine, Baltimore, MD, United States, \\ ${ }^{3}$ Department of Molecular, Developmental and Cell Biology, University of California, Santa Barbara, Santa Barbara, CA, \\ United States, ${ }^{4}$ Translational Neuroscience Facility, School of Medical Sciences, University of New South Wales, Sydney, \\ NSW, Australia, ${ }^{5}$ Neuroscience Research Institute, University of California, Santa Barbara, Santa Barbara, CA, United States
}

Immediate early and constitutively expressed products of the Homer1 gene regulate the functional assembly of post-synaptic density proteins at glutamatergic synapses to influence excitatory neurotransmission and synaptic plasticity. Earlier studies of Homer1 gene knock-out (KO) mice indicated active, but distinct, roles for IEG and constitutively expressed Homer1 gene products in regulating cognitive, emotional, motivational and sensorimotor processing, as well as behavioral and neurochemical sensitivity to cocaine. More recent characterization of transgenic mice engineered to prevent generation of the IEG form (a.k.a Homer1a KO) pose a critical role for Homer1a in cocaine-induced behavioral and neurochemical sensitization of relevance to drug addiction and related neuropsychiatric disorders. Here, we extend our characterization of the Homer1a KO mouse and report a modest pro-depressant phenotype, but no deleterious effects of the $\mathrm{KO}$ upon spatial learning/memory, prepulse inhibition, or cocaine-induced place-conditioning. As we reported previously, Homer1a KO mice did not develop cocaine-induced behavioral or neurochemical sensitization within the nucleus accumbens; however, virus-mediated Homer1a over-expression within the nucleus accumbens reversed the sensitization phenotype of KO mice. We also report several neurochemical abnormalities within the nucleus accumbens of Homer1a KO mice that include: elevated basal dopamine and reduced basal glutamate content, Group1 mGluR agonist-induced glutamate release and high $\mathrm{K}^{+}$-stimulated release of dopamine and glutamate within this region. Many of the neurochemical anomalies exhibited by Homer1a KO mice are recapitulated upon deletion of the entire Homer1 gene; however, Homer1 deletion did not affect NAC dopamine or alter $\mathrm{K}^{+}$-stimulated neurotransmitter release within this region. These data show that the selective deletion of Homer1a produces a behavioral and neurochemical phenotype that is distinguishable from that produced by deletion of the entire Homer1 gene. Moreover, the data indicate a specific role for Homer1a in regulating cocaine-induced behavioral and neurochemical sensitization of potential relevance to the psychotogenic properties of this drug. 


\section{INTRODUCTION}

The mammalian gene Homer1 possesses 10 exons, the regulated transcription of which results in both constitutively expressed and immediate early gene (IEG) products (Brakeman et al., 1997; Kato et al., 1998; Bottai et al., 2002). Exons 1-5 encode an Enabled/vasodilator-stimulated phosphoprotein (Vasp) homology 1 (EVH1) domain (Beneken et al., 2000). This EVH1 domain exhibits a RxxxxxGLGF sequence that enables Homer interactions with a proline-rich sequence (PPSPF) displayed by proteins regulating neuronal morphology, synaptic architecture, and glutamate receptor signaling/intracellular calcium dynamics (Shiraishi-Yamaguchi and Furuichi, 2007; Worley et al., 2007; Szumlinski et al., 2008a; Fagni, 2012; cf. Constantin, 2016). Exons 6-10 encode the carboxyl-tail of Homer proteins that consists of a coiled-coil (CC) domain, two leucine zipper motifs, and the 3' UTR (Kato et al., 1998; Xiao et al., 1998; Soloviev et al., 2000). This CC-domain enables Homer proteins to tetramerize (Hayashi et al., 2006) - a property necessary for maintaining the functional architecture of glutamate synapses (for reviews, Shiraishi-Yamaguchi and Furuichi, 2007; Worley et al., 2007; Szumlinski et al., 2008a; Fagni, 2012; Constantin, 2016).

Alternative transcript splicing in regions downstream from exon 5 and premature termination of gene transcription has been reported for all three Homer genes (Homer1, Homer2, Homer3) (Soloviev et al., 2000). However, this phenomenon has been best-described for the Homer1 gene (Brakeman et al., 1997; Bottai et al., 2002). The premature termination of Homer1 transcription results in truncated or "short" Homerl isoforms, so named because they lack the CC- and leucine zipper motifs necessary to multimerize, of which Homerla and ania-3 have been identified in brain (Brakeman et al., 1997; Berke et al., 1998; Soloviev et al., 2000). The induction of these IEG Homer1 isoforms (i.e., Homerla and ania-3) upon synaptic activity serves a dominant negative function by displacing CC-Homer proteins from their EVH1-bound partners. While this dynamic expression is predicted to cause a temporary reduction in the efficacy of post-synaptic glutamate transmission, by virtue of their inability to tetramerize, IEG Homer induction enables the trafficking to, and lateral movement within, the plasma membrane of glutamate receptors and associated signaling molecules. Thus, the induction of IEG Homer isoforms is critical for synaptic rearrangement and neuroplasticity (for reviews, Shiraishi-Yamaguchi and Furuichi, 2007; Fagni, 2012; Marton et al., 2015).

Converging evidence from clinical and behavioral/neural genetic studies in animals support active roles for members of the Homer family of post-synaptic scaffolding proteins in regulating various aspects of behavior, as well as drug-induced neuroplasticity relevant to addiction (for reviews, Szumlinski et al., 2008a; Marton et al., 2015). IEG Homer isoforms are induced in mesocorticolimbic structures by acute treatment with various drugs of abuse (see Szumlinski et al., 2008a; Marton et al., 2015). However, our understanding of their functional significance for addiction-related behavioral and neuropathology is rather limited. Earlier virus-mediated gene transfer studies failed to detect significant effects of Homerla over-expression upon cocaine-induced locomotor hyperactivity/sensitization in rodent models (Lominac et al., 2005; Szumlinski et al., 2006). In contrast, behavioral phenotyping of transgenic mice over-expressing Homerla selectively within striatal striosomes supported an active role for Homerla in acute amphetamineelicited locomotion, as well as in the expression of anxiety (Tappe and Kuner, 2006). The behavioral phenotype of striatal Homerla over-expressing mice is consistent with those reported previously for Homer1 whole-gene deletion (Szumlinski et al., 2004, 2005a; Lominac et al., 2005), as well as for rats infused intraaccumbens with oligonucleotides against Homer1 (Ghasemzadeh et al., 2003), providing support for a competitive interaction between IEG and CC-Homer1 isoforms in regulating addictionrelated emotional and motivational processing (Marton et al., 2015).

Herein, we provide a more complete behavioral and neurochemical phenotyping of a transgenic mouse engineered to prevent expression of Homerla (Homer1 $a^{-/-}$) while retaining expression of Homerlc (Hu et al., 2010). Homerla $a^{-/-}$mice do not exhibit cocaine-induced locomotor or neurochemical sensitization within the NAC (Park et al., 2013). Here, we relate this resiliency to the dysregulation of NAC extracellular dopamine and glutamate and, demonstrate, using an adenoassociated virus (AAV) strategy, an active role for Homerla induction within the NAC in regulating cocaine-induced neuroplasticity of relevance to addiction and related mental disorders.

\section{MATERIALS AND METHODS}

\subsection{Subjects}

Homerla $^{+/+}$, Homerla $a^{+/-}$, and Homerla $a^{-/-}$mice (on a mixed C57BL/6J × 129Xi/SvJ background; see Hu et al., 2010 for details), as well as Homer1 $1^{+/+}$and Homer1 $1^{-/-}$mice (on a mixed $\mathrm{BALB} / \mathrm{cJ} \times \mathrm{C} 57 \mathrm{BL} / 6 \mathrm{~J} \times 129 \mathrm{Xi} / \mathrm{SvJ}$ background; see Yuan et al., 2003 for details) were bred in-house at UCSB from mating of heterozygous breeder pairs and both male and female littermates were employed in all studies. The primers for genotyping Homer1 $a^{-/-}$mice are: H1F: CACCCGATGTGACACAGAAC, H1cR: CCAGTAATGCCACGGTACG, H1aR298: CACTGCTT CACATTGGCAGT. Wild-type band $(\mathrm{H} 1 \mathrm{~F} / \mathrm{H} 1 \mathrm{cR})$ is at $602 \mathrm{bp}$ and $\mathrm{KO}$ band $(\mathrm{H} 1 \mathrm{~F} / \mathrm{H} 1 \mathrm{aR} 298)$ is at $211 \mathrm{bp}$. The primers for genotyping Homer1 $1^{-/-}$mice are: 84: CAATGCATG CAATTCCTGAG, 85: CGAGAAACTTACATATATCCGCAAA, 86: GAACTTCGCGCTATAACTTCG. Wild-type band $(\mathrm{H} 1 \mathrm{~F} / \mathrm{H} 1 \mathrm{cR})$ is at $602 \mathrm{bp}$ and $\mathrm{KO}$ band $(\mathrm{H} 1 \mathrm{~F} / \mathrm{H} 1 \mathrm{aR} 298)$ is at $211 \mathrm{bp}$. To reduce litter confounds, mice were selected from a minimum of four different litters within each replicate and testing began when mice were 7-8 weeks of age. Animals were group-housed in polyethylene cages in a temperature $\left(25^{\circ}\right)$ and humidity $(71 \%)$ controlled vivarium under a $12 \mathrm{~h}$ dark/light cycle (lights off: 7:00 A.M.) with food and water available ad libitum. Experimental protocols, as well as housing and animal care, were consistent with the guidelines provided by the National Institute of Health (NIH) Guide for Care and Use of Laboratory Animals. All experiments were approved by the Institutional Animal Care and Use Committee of University of California, Santa Barbara. 


\subsection{Behavioral Test Battery}

Male and female Homer1a $a^{+/}$, Homer1a $a^{+-}$, Homer1a $a^{-/-}$ littermates were subjected to a behavioral test battery consisting of various conventional paradigms to assay anxiety-like behavior (elevated plus maze, reactivity to a novel object), depressivelike behavior (Porsolt swim test, saccharin preference), spatial learning and memory (Morris water maze), and sensorimotor processing/gating (acoustic startle and pre-pulse inhibition of acoustic startle/PPI). With the exception of the saccharin preference test, the procedures for each of these paradigms are detailed in our published work (see Szumlinski et al., 2004, 2005a; Lominac et al., 2005; Ary et al., 2013; Lee et al., 2015; Guo et al., 2016).

In brief, for the elevated plus maze, mice were placed on the center intersection of the maze with two white open arms and two black-walled arms $24 \mathrm{~cm}$ high. Each arm measured $123 \mathrm{~cm}$ long by $5 \mathrm{~cm}$ wide. Behavior in the apparatus was monitored for a $5 \mathrm{~min}$ trial (Lee et al., 2015; Guo et al., 2016). For the reactivity to a novel object test, mice were placed into a black Plexiglas $(40 \mathrm{~cm} \times 40 \mathrm{~cm} \times 30 \mathrm{~cm})$ open-field arena, containing an inedible object in the center. Mice were allowed to explore the arena for $2 \mathrm{~min}$ and the amount of time spent investigating the object, as well as the number of object contacts were recorded (Ary et al., 2013; Lee et al., 2015). For the Porsolt swim test, mice were placed into Plexiglas buckets $(23 \mathrm{~cm} \times 24 \mathrm{~cm} \times 22 \mathrm{~cm})$ and the behavior of the mice was scored in 30-s intervals using a checklist for swimming or floating over a 15-min period (Lominac et al., 2005; Szumlinski et al., 2005a; Ary et al., 2013; Guo et al., 2016). For the saccharin preference test, mice were presented with two $50 \mathrm{ml}$ sipper tubes, one containing tap water and the other containing a $0.16 \% \mathrm{w} / \mathrm{v}$ saccharin solution for $24 \mathrm{~h}$ in the home cage. Bottle weights before and after the 24$\mathrm{h}$ drinking period gauged the volume consumed and were used to calculate the preference for the saccharin solution. For the Morris water maze, we employed a stainless steel circular tank (200 cm in diameter, $60 \mathrm{~cm}$ in height; painted white on the inside and filled with room temperature water to a depth of $40 \mathrm{~cm}$ ), with salient extra maze cues located on all four walls of the room in which the maze was located. A clear platform was placed in the tank and its location remained fixed throughout the course of the experiment. For 4 days, mice were trained four times a day (once at each compass point) to locate the hidden platform. During each trial, mice were randomly placed in the pool at one of the four compass points and swimming was recorded digitally by a video camera mounted on the ceiling directly above the pool (ANY-Maze, Stoelting). Training sessions were $120 \mathrm{~s}$ in duration; if the mice were unable to locate the platform during the allotted time, they were guided to the platform where they remained for $30 \mathrm{~s}$. At $24 \mathrm{~h}$ after the last training trial, a 120s memory probe test was performed in which the platform was removed and the amount of time taken by the mouse to swim toward the platform location and the time spent swimming in the platform quadrant was recorded (Lominac et al., 2005; Ary et al., 2013). For the acoustic startle/PPI experiment, we presented six different trial types: startle pulse (st110, $110 \mathrm{~dB} / 40 \mathrm{~ms}$ ), low prepulse stimulus given alone (st74, $74 \mathrm{~dB} / 20 \mathrm{~ms}$ ), high prepulse stimulus given alone (st90, $90 \mathrm{~dB} / 20 \mathrm{~ms}$ ), st74 or st90 given $100 \mathrm{~ms}$ before the onset of the startle pulse (pp74 and pp90, respectively), and no acoustic stimulus (i.e., only background noise was presented; st0). St100, st0, pp74, and pp90 trials were applied 10 times, st74 and st90 trials were applied five times, with trials randomly administered [average intertrial interval was $15 \mathrm{~s}(10-20 \mathrm{~s})$ ]. The background noise of each chamber was $70 \mathrm{~dB}$. The data for startle amplitude were averaged across stimulus trials and the percent inhibition of the $110 \mathrm{~dB}$ startle by the 74 and $90 \mathrm{~dB}$ prepulse intensities was calculated for each animal to index PPI (Szumlinski et al., 2005a; Guo et al., 2016).

For studies of Homer $1 a^{+/+,+/-,-/-}$mice, behavioral testing occurred across days, with several tests conducted per day, spaced 4-6 h apart. The order of testing was the same for each cohort of animals: Day 1: PPI, reactivity to novel objects, Day 2: elevated plus-maze, and Porsolt swim test. Mice were then allowed 23 days recovery from the Porsolt swim test and then tested for their ability to habituate to repeated placement within a novel activity chamber $(30 \mathrm{~cm} \times 30 \mathrm{~cm} \times 45 \mathrm{~cm} ; 30 \mathrm{~min}$ sessions over 5 days). As the Porsolt swim test was predicted to reduce performance in a Morris water maze, a separate cohort of Homer $1 a^{+/+,+/-,-/-}$mice were trained (4, 2-min trials/day for 4 days) and then tested in the Morris water maze (2-min test) (see Lominac et al., 2005). Acoustic acuity was also assayed in a distinct cohort of male Homer $1 a^{+/+,+/-,-/-}$mice by randomly presenting acoustic stimuli ranging in intensity from 0 to $125 \mathrm{~dB}$ within the acoustic startle chambers during a 20min session. Following this session, this cohort of animals were assayed for saccharin preference by presenting mice with two $50 \mathrm{ml}$ sipper tubes in the home cage (water vs. $0.125 \% \mathrm{w} / \mathrm{v}$ saccharin) under continuous-access procedures over the course of 8 days. With the exception of this last cohort of mice, all behavioral experiments included approximately equal numbers of male and female subjects (minimum $n=6 /$ sex/genotype) and sex was included as a between-subjects variable during data analysis by analyses of variance (ANOVA). However, with the exception of the novel object test, no sex differences in behavior were observed and thus, the data are presented collapsed across sex for the majority of the experiments.

For behavioral paradigms in which genotypic differences were observed, the experiment was replicated in Homer $1 a^{+/+}$and Homer1a $a^{-/}$mice infused intra-NAC with an AAV carrying Homer1a cDNA (AAV-Homer1a) or a scrambled control (AAVcontrol; see section 2.4 below) to confirm an active role for this IEG isoform in regulating behavior. For these follow-up studies, behavioral testing commenced a minimum of 3 weeks following $\mathrm{AAV}$ infusion and mice were assayed for acoustic startle/PPI, followed by the Porsolt swim test. As behavior in the Morris Water Maze test relies heavily upon hippocampal, rather than accumbens, function, AAV-infused mice were not tested in this assay.

\subsection{Cocaine-Induced Place-Conditioning}

A separate cohort of male and female Homerla $a^{+/,+/-,-/-}$ mice were used to index for genotypic differences in cocaineconditioned reward using cocaine-induced place-conditioning. 
The procedures to elicit place-conditioning were identical to those described previously by our group (e.g., Ary et al., 2013), with separate groups of mice injected with intraperitoneal (i.p.) injections of 3,10 , or $30 \mathrm{mg} / \mathrm{kg}$ cocaine (National Institute on Drug Abuse, Bethesda, MD, United States). Animals were habituated to both compartments of the two-compartment apparatus for $15 \mathrm{~min}$ during a pre-conditioning testing (PreTest) and then were subjected to daily, 15-min, conditioning sessions, alternating between cocaine and saline, over the course of 8 days. The day following the last conditioning session, animals were allowed free-access to both compartments in a post-conditioning test. The behavior of the mice was recorded throughout the experiment using a digital video-tracking system and ANYMaze software (Stoelting, Co., Wood Dale, IL, United States). The difference in the time spent in the cocaine- versus saline-paired compartment on a post-conditioning test served to index cocaine reward/aversion (Conditioned Place-Preference Score or CPP Score). The data were analyzed using a Genotype $(+/+,+/-$, $-/-) \times \operatorname{Sex} \times \operatorname{Dose}(3,10$, and $30 \mathrm{mg} / \mathrm{kg}$ cocaine $) \times$ Side (paired vs. unpaired) ANOVA, with repeated measures on the Side factor. The data for locomotor activity during the PreTest and cocaine-induced locomotion were published previously in Park et al. (2013). A follow-up study employed identical placeconditioning procedures to assay the effects of intra-NAC AAVHomer1a infusion upon genotypic differences in novelty-induced locomotion during the PreTest, habituation of locomotor activity (changes in saline-induced locomotion observed during the four saline-conditioning sessions), sensitization of cocaine-induced locomotor hyperactivity (changes in locomotor activity observed during the four cocaine-conditioning sessions; $10 \mathrm{mg} / \mathrm{kg}$ ) and cocaine-conditioned reward (CPP Score following conditioning).

\subsection{Construction of AAV-Homer1a}

The rat Homerla coding sequence was amplified using wholebrain CDNA, and the PCR was product expressed as an $\mathrm{N}$-terminal fusion protein with the hemagglutinin (HA)-tag in a rAAV backbone containing the $1.1 \mathrm{~kb} C M V$ enhancer/chickenactin (CBA) promoter, 800 bp human interferon scaffold attachment region inserted 5_ of the promoter, the woodchuck post-transcriptional regulatory element (WPRE), and the bovine growth hormone polyA flanked by inverted terminal repeats (AAV-Homer1a, AAV-Homer1c). The same AAV-CBA-WPREbGH backbone encoding the enhanced green fluorescent protein (EGFP) was used as control (AAV-GFP). As described previously (Hauck et al., 2003), AAV pseudotyped vectors virions containing a 1:1 ratio of AAV1 and AAV2 capsid proteins with AAV2 intertrigeminal regions were generated. For this, human embryonic kidney 293 cells were transfected with the AAV cisplasmid, the AAV1 (pH21) and AAV2 (pRV1) helper plasmids ( $\mathrm{pF} 6$ ), and the adenovirus helper plasmid by standard calcium phosphate transfection methods. Cells were harvested at $48 \mathrm{~h}$ after transfection, and the vector purified using heparin affinity columns as described previously (During et al., 2003). As also described previously (Clark et al., 1999), genomic titers were determined using the Prism 7700 sequence detector system (Applied Biosystems, Foster City, CA, United States) with primers designed to WPRE.

\subsection{Surgical Procedures and AAV Infusion}

The NAC is a limbic structure implicated in both the psychomotor-activing and rewarding/reinforcing properties of drugs of abuse (e.g., Morein-Zamir and Robbins, 2015; Scofield et al., 2016). Homerla is induced within the NAC by various drugs of abuse (Szumlinski et al., 2008a; Marton et al., 2015) and Homer1a $a^{-/-}$mice exhibit impaired cocaine-induced neurochemical sensitization within this region (Park et al., 2013). Thus, under isoflurane anesthesia, we conducted craniotomies to implant bilateral guide cannulae (20-gauge; 10 -mm long), $2 \mathrm{~mm}$ above the NAC of mice (see Lominac et al., 2005; Cozzoli et al., 2009; Ary et al., 2013), for the purposes of conducting in vivo microdialysis measurement of glutamate and dopamine (see section 2.6 below) and/or infusing AAVs carrying either cDNA for Homerla (AAV-Homer1a) or a scrambled DNA sequence as a control (AAV-control) to determine an active role for NAC Homerla expression in regulating neurochemistry and behavior (see Lominac et al., 2005; Cozzoli et al., 2009 for AAV details). A Kopf stereotaxic device held the animal's head level and holes were drilled based on coordinates from bregma: (AP: $+1.3 \mathrm{~mm}$; ML: $\pm 1.0 \mathrm{~mm}$; DV: $-2.3 \mathrm{~mm}$ ) (Paxinos and Franklin, 2013). Guide cannulae were fixed to the skull with dental resin, surgical incisions were closed with a tissue adhesive.

For AAV-naïve mice undergoing microdialysis procedures, dummy cannulae (24 gauge; length equivalent to guide cannulae) was then placed inside the guide cannulae to prevent contamination or blockade and animals were allowed a minimum of 5 days recovery prior to neurochemical testing. Our AAVs are considered BSL1 and thus, standard protective personal equipment were employed during AAV infusion. For animals receiving AAV infusions, microinjectors (33-gauge, $12 \mathrm{~mm}$ long) where then lowered down the guide cannulae and the AAVs infused at a rate of $0.05 \mu \mathrm{l} / \mathrm{min}$ for $5 \mathrm{~min}$ (total volume $/$ side $=0.25 \mu \mathrm{l})$. Microinjectors were left in place for an additional $5 \mathrm{~min}$ to allow for diffusion away from the microinjector tip prior to removal and occlusion of the guide cannulae. AAV-infused mice were allowed a minimum of 3 weeks recovery to achieve maximal neuronal transduction (Klugmann and Szumlinski, 2008). AAV transduction within the NAC was verified using standard immunohistochemical staining procedures for the hemagglutanin (HA) tag using a mouse anti-HA primary antibody (Covance, Princeton, NJ, United States), and straining visualized using a M.O.M. Detection Kit (Vector Laboratories, Burlingame, CA, United States), as conducted previously (Szumlinski et al., 2004, 2005b, 2017; Lominac et al., 2005; Cozzoli et al., 2009; Ary et al., 2013).

\subsection{In Vivo Microdialysis}

Homer $1 a^{-/-}$mice do not exhibit cocaine-induced dopamine or glutamate sensitization in the NAC (Park et al., 2013). Thus, a series of in vivo microdialysis experiments were conducted to relate this sensitization-resistant phenotype to biochemical indices of neuronal function within this region. For all in 
vivo microdialysis experiments, a microdialysis probe (24 gauge; $12 \mathrm{~mm}$ in length with $\sim 1.0 \mathrm{~mm}$ active membrane) was lowered unilaterally into one of the guide cannulae and perfused with artificial CSF (146 nM NaCl, $1.2 \mathrm{mM} \mathrm{CaCl}_{2}, 2.7 \mathrm{mM} \mathrm{KCl}$, $1.0 \mathrm{mM} \mathrm{MgCl}, \mathrm{pH}=7.4$ ) at a rate of $2 \mu \mathrm{l} / \mathrm{min}$. Dialysate collection began after $3 \mathrm{~h}$ of probe equilibration and occurred in $20 \mathrm{~min}$ intervals into vials containing $10 \mu \mathrm{l}$ of preservative [10\% methanol (v/v), 15\% acetonitrile (v/v), $150 \mathrm{mM} \mathrm{NaPO}_{4}$, $4.76 \mathrm{mM}$ citric acid, $3 \mathrm{mM}$ SDS, $50 \mathrm{mM}$ EDTA, $\mathrm{pH}=5.6]$. Dialysate was stored at $-80^{\circ} \mathrm{C}$ until analysis by HPLC (see section 2.6 below). Microdialysis probe localization within the NAC was verified using standard cresyl violet staining procedures (for AAV-naïve mice) or upon immunohistochemical localization of AAV transduction (see above), followed by examination of tissue under light microscope. In nearly all subjects, microdialysis probes were localized primarily to the shell subregion or to the interface between the shell and core subregions (see section 3).

\subsubsection{DHPG-Stimulated Glutamate Release}

Homer proteins are critical regulators of mGlu1/5 function in vitro and in vivo (cf. Ango et al., 2000, 2001; ShiraishiYamaguchi and Furuichi, 2007; Worley et al., 2007; Szumlinski et al., 2008a; Fagni, 2012; Constantin, 2016). Thus, we compared the effects of Homer1a versus pan-Homer1 deletion upon an in vivo index of mGlu1/5 function - agonist-stimulated glutamate release (Swanson et al., 2001; Szumlinski et al., 2004, 2017). For this, Homer1a $a^{+/+,-/-}$and pan-Homer $1^{+/+,-/-}$mice were perfused within increasing concentrations of the mGlu1/5 agonist DHPG [(S)-3,5-dihydroxyphenylglycine; 0, 3, 30, and $300 \mu \mathrm{M}$; Tocris Cookson, Ballwin, MO, United States], via the microdialysis probe in 1 -h intervals. For each mutant line, the data were analyzed using Genotype (+/+ vs. -/-) $\times$ DHPG ANOVA, with repeated measures on the DHPG factor (four levels).

\subsubsection{Depolarization-Induced Dopamine and Glutamate Release}

To relate the distinct neurochemical phenotypes of Homer1a (Park et al., 2013) versus Homer1 (Szumlinski et al., 2004, 2005a) mutants to the excitability of dopamine and glutamate terminals within the NAC, we compared depolarization-induced neurotransmitter release by locally infusing high $\mathrm{K}^{+}$solutions (50 and $100 \mathrm{mM}$; Sigma-Aldrich, St. Louis, MO, United States) through the microdialysis probe in 1-h intervals (e.g., He and Shippenberg, 2000). To conserve animal numbers, this microdialysis experiment was conducted 3-4 days following the DHPG study described in Section 2.6.1 above, using the other side of the head. The data were analyzed separately for each mutant line using a Genotype $\times \mathrm{K}^{+}$ANOVA, with repeated measures on the $\mathrm{K}^{+}$factor (three levels).

\subsubsection{Glutamate No Net-Flux Procedures}

Pan-Homer1 deletion reduces basal extracellular glutamate content within the NAC of mice (Szumlinski et al., 2005a) and prior conventional in vivo microdialysis studies suggested lower basal extracellular glutamate content within the NAC also of Homer1a $a^{-/-}$animals (Park et al., 2013). However, estimates of basal neurotransmitter levels assessed under conventional microdialysis procedures are subject to differences in probe recovery (Parsons and Justice, 1992). Thus, we quantified the effects of Homer1a deletion upon the basal extracellular glutamate content within the NAC using no net-flux procedures (Szumlinski et al., 2004, 2005a, 2017; Lominac et al., 2005; Ary et al., 2013). For this, increasing concentrations of glutamate $(2.5,5$, and $10 \mu \mathrm{M})$ were infused through the probe in ascending order for $1 \mathrm{~h}$ each. Linear regression analyses were then conducted on the plot of the average net-flux of glutamate at each glutamate concentration versus the concentration of glutamate infused through the probe and the point of no net-flux $(y=0$; estimate of basal extracellular levels of glutamate), as well as the slope of regression lines (estimate of glutamate clearance), were determined and analyzed using independent samples $t$-tests. A follow-up experiment determined how an intra-NAC AAVHomerla infusion altered the genotypic differences in our dependent measures in this assay. This follow-up study employed identical no net-flux procedures as those employed in the original genotypic comparison, with the exceptions that the Homerla $a^{+/+,-/-}$mice were infused intra-NAC with either AAV-control or -Homerla, a minimum of 3 weeks prior to probe insertion and the data were analyzed using an AAV (control vs. Homerla) $\times$ Genotype (+/+ vs. -/-) ANOVA.

\subsubsection{Cocaine-Induced Sensitization of Dopamine and Glutamate within the NAC}

To determine whether or not Homerla within the NAC actively regulates the development of cocaine-induced dopamine and glutamate sensitization in this region, Homer $1 a^{+/+}$and Homer $1 a^{-/-}$mice were infused with AAV-control or -Homerla and then conventional in vivo microdialysis procedures were conducted a minimum of 3 weeks later. Low fecundity in our Homerla colony at the time of study forced us to conserve animal numbers and thus, microdialysis procedures were conducted in the same AAV-infused mice as those tested for cocaine-induced locomotor sensitization/place-preference (see section 2.3). In order to accommodate both paradigms, mice first underwent a microdialysis session to assay the effects of AAV infusion upon the neurochemical response to an acute injection of $30 \mathrm{mg} / \mathrm{kg}$ cocaine (i.p.). Following a 3-h equilibration period, baseline sampling was conducted over an hour and then mice were injected with cocaine and samples collected for $3 \mathrm{~h}$ thereafter. At the end of this first microdialysis session, the probe was removed and mice were allowed to recover for 2 days prior to the 10-day place-conditioning procedure (consisting of four alternating injections of saline and $30 \mathrm{mg} / \mathrm{kg}$ cocaine). One to 2 days following the post-conditioning test, a second microdialysis session was conducted using the opposite side of the head to assay for cocaine-induced neurochemical sensitization.

In contrast to our prior study (Park et al., 2013), the Homer1a $a^{+/+,-/-}$mice in this study were treated with a total of six injections of $30 \mathrm{mg} / \mathrm{kg}$ cocaine. Due to technical 
issues associated with subject attrition and sample loss due to technical difficulties with the HPLC, not all mice were tested for cocaine-induced neurochemical changes during both microdialysis sessions. Thus, in order to include all of the remaining the mice tested, Injection Number was treated as a between-subjects variable. As group differences were not observed for baseline glutamate levels on either injection, the data were expressed as a percent of baseline values for each group and to facilitate visualization of group differences in the magnitude of the cocaine-induced rise in dopamine and glutamate, the area under the curve (AUC) was employed in the statistical analyses of the results (Lominac et al., 2012; Shin et al., 2016). Thus, for both baseline neurotransmitter levels and the AUC for cocaine-induced changes in neurotransmitter levels, the data were analyzed using a Genotype $\times \mathrm{AAV} \times$ Injection Number between-subjects ANOVA.

\subsection{High Pressure Liquid Chromatography}

The high pressure liquid chromatography (HPLC) system and procedures for the electrochemical detection of glutamate and dopamine in the dialysate of mice, as well as the chromatographic analysis of the data, were identical to those described previously by our group (Lominac et al., 2012, 2014; Ary et al., 2013; Szumlinski et al., 2017). Each HPLC system consisted of a Coularray detector, a Model 542 autosampler and two Model 582 solvent delivery systems (ESA/Thermo-Fisher), with a detection limit of $0.01 \mathrm{fg} / \mathrm{sample}(20 \mu \mathrm{l} / \mathrm{sample}$ onto column $)$. For analysis of dopamine, the MD-TM mobile phase was employed (ESA/Thermo-Fisher), and neurotransmitters in $30 \mu \mathrm{l}$ from each $50 \mu \mathrm{l}$ sample were separated using a MD-150 mm $\times 3.2 \mathrm{~mm}$ column (ESA/Thermo-Fisher). An ESA/Thermo-Fisher 5014B analytical cell was used for the detection of monoamines (oxidation and reduction electrode potentials of +220 and $-150 \mathrm{mV}$, respectively). For glutamate, the mobile phase consisted of 3.5\% acetonitrile (v/v), 22\% methanol (v/v), $100 \mathrm{mM}$ $\mathrm{NaPO}_{4}, \mathrm{pH}=6.75$. A reversed phase column $(50 \mathrm{~mm} \times 3.0 \mathrm{~mm}$ Capcell PAK; Shiseido, Tokyo, Japan) was used to separate the amino acids, and precolumn derivatization with $o$-phthaladehyde $(2.7 \mathrm{mg} / \mathrm{ml})$ of the $20 \mu \mathrm{l}$ from each $50 \mu \mathrm{l}$ sample was performed using an ESA Model 540 autosampler (ESA/Thermo-Fisher). Glutamate was detected using an electrochemical analytical cell with an oxidizing potential of $+550 \mathrm{mV}$. Glutamate and dopamine content in each sample were analyzed by peak height and compared with an external standard curve for quantification (glutamate standards: 2.5, 5.0, $10 \mathrm{mM}$; dopamine standards: 1.25, 2.5, $5 \mathrm{nM}$ ).

\subsection{General Statistical Approaches}

As detailed above, the majority of data were analyzed using ANOVAs, with repeated measures as appropriate for the experimental design. Significant interactions were deconstructed along the relevant factors, and significant main effects were followed by least significant differences (LSDs) post hoc tests or $t$-tests, as appropriate for the number of comparisons. $\alpha=0.05$ for all analyses.

\section{RESULTS}

\subsection{Negative Affect}

Exposure to a novel environment induces Homerla expression within forebrain (Vazdarjanova et al., 2002) and pan-Homer1 KO mice exhibit robust signs of hyper-emotionality across a variety of behavioral paradigms (Szumlinski et al., 2004, 2005a; Lominac et al., 2005). Thus, we first assayed Homer1a ${ }^{+/+}$and Homer1a $a^{-/}$mice for behavioral signs of negative affect using a comparable behavioral test battery as that employed in our previous work. As detailed below, the results do not support a consistent role for Homerla induction in the manifestation of anxiety- or depressive-like behaviors in mice.

\subsubsection{Elevated Plus Maze}

When tested in the elevated plus maze test, no main effects or interactions with sex were detected ( $p>0.05$ for all variables); thus, the data for male and female mice were collapsed for data presentation. Homer $1 a^{+/-}$mice exhibited a significant increase in open arm entries, relative to both Homer $1 a^{+/+}$and Homer1a $a^{-/-}$mice (Figure 1A) [Genotype effect: $F(1,79)=4.50$, $p=0.01$; LSD post hoc tests]. A similar pattern of genotypic differences was observed for the time spent in the open arms, but the result was shy of statistical significance (Figure 1B; Genotype effect: $p=0.1$ ).

\subsubsection{Novel Object Test}

In the novel object test assay, females exhibited lower behavioral indices of anxiety than males, as indicated by a significant increase in both the time in object contact [Sex effect: $F(1,59)=18.91, p<0.0001]$, and number of object contacts [Sex effect: $F(1,59)=36.50, p<0.0001]$. No sex difference was observed for the latency to first make contact with the novel object ( $p=0.31)$ and, as illustrated in Figure 1C (females) and Figure 1D (males), genotypic differences in exploratory behavior were not observed for either sex ( $p>0.20$ for all variables).

\subsubsection{Porsolt Swim Test}

No sex differences were observed for any of the variables measured during Porsolt Swim testing (Sex effects and interactions, $p$ 's $>0.05)$. Thus, the data were collapsed across sex for presentation. Homer1a deletion reduced the latency to first float during both the 15-min exposure session, as well as during the 5-min re-exposure session conducted $24 \mathrm{~h}$ later (Figure 1E), with both Homer $1 a^{+/-}$and Homer $1 a^{-/-}$mice exhibiting a shorter latency to float, compared to controls [Test effect: $p=0.08$; Genotype effect: $F(2,51)=6.5, p=0.003$; Genotype $\times$ Test: $p=0.93$ ]. However, no genotypic differences were observed regarding the total floating during either session (Figure 1F) [Test effect: $F(1,51)=3.93, p=0.05$; Genotype effect and Genotype $\times$ Test: $p>0.31$.

\subsubsection{Saccharin Preference}

Although the results of the Porsolt swim test suggested greater depressive-like behavior in Homer $1 a^{-/-}$mice, we failed to detect genotypic differences in the initial or average preference for a palatable saccharin solution over water (for both variables, 

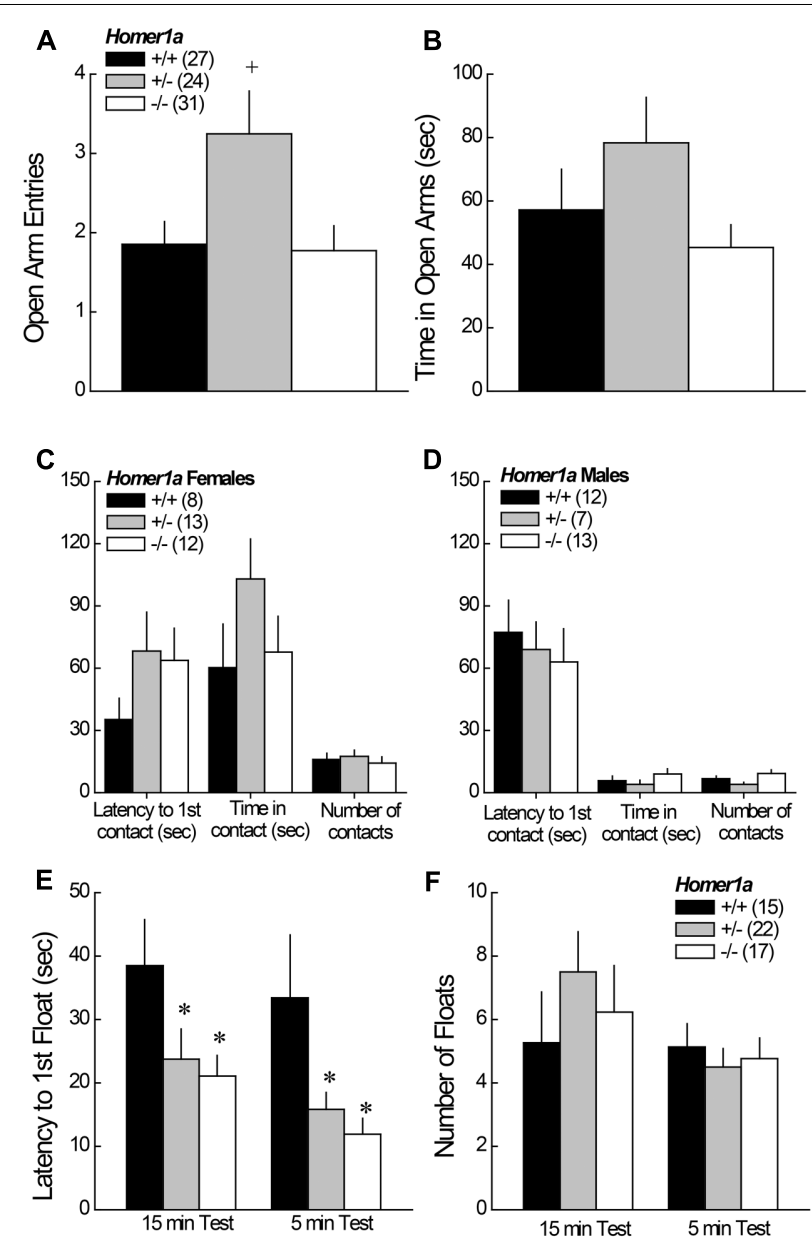

FIGURE 1 | Anxiety-like behavior in Homer1a+/+, Homer1a+/-, and Homer1a- ${ }^{-1}$ mice. When compared in an elevated plus maze test, Homer1a+/- mice exhibited relatively lower anxiety as indicated by greater (A) number of open arm entries and (B) time spent in the open arms. While no sex differences in anxiety-like behavior were observed on the elevated plus maze, females (C) exhibited greater anxiety than males (D), in the novel object test, but no genotypic differences were observed. No sex differences were apparent in the Porsolt Swim test, however, Homer1a deletion increased (E) the latency to first float, without influencing the total amount of floating (F). The data represent the mean \pm SEM of the number of mice indicated in parentheses. ${ }^{*} p<0.05$ vs. $+/+;+p<0.05$ vs. $+/+$ and $-/-$ (LSD post hoc tests).

Genotype effects, $p>0.25)$, with the average preference exhibited by Homerla $a^{+/+}$, Homerla $a^{+/-}$, and Homer1a $a^{-/-}$mice being $43.1 \pm 3.80,50.90 \pm 2.49$, and $45.11 \pm 4.48 \%$, respectively.

\subsubsection{Habituation to a Novel Environment}

As the above data argue an inconsistent role for Homerla in mediating the behavioral response to an acute mild stressor, we next determined whether Homerla deletion might impair the ability to habituate to the repeated presentation of a mild stressor using a simple locomotor habituation paradigm. No significant main effects of, or interactions with, the Sex factor were observed ( $p$ 's $>0.15$ ). While there were trends for reduced overall locomotor activity in Homer $1 a^{+/-}$and
Homer1a $a^{-/-}$mice, this genotypic difference was not significant nor were there genotypic differences in the extent to which animals habituated with repeated testing (data not shown) [Session effect: $F(4,208)=23.41, p<0.0001$; Genotype effect and Genotype $\times$ Session, $p>0.05]$. Further, no genotypic differences were observed for the change in the latency to enter the center zone (data not shown) [Session effect: $p=0.09$; Genotype $\times$ Session, $p>0.05$ ] or in the number of entries into the center zone of the activity monitors with repeated testing (data not shown) [Session effect: $F(4,52)=5.33, p<0.0001$; Genotype $\times$ Session: $p>0.95$ ]

\subsection{Sensorimotor Processing}

Pan-Homer1 knock-out mice exhibit marked deficits in sensorimotor-gating (Szumlinski et al., 2004, 2005a; Lominac et al., 2005). Thus, we determined the effects of Homerla deletion upon acoustic startle and pre-pulse inhibition of acoustic startle (PPI). Again, we failed to detect a sex difference in behavior (for all variables, no Sex effect or interactions, $p>0.30$ ), thus, the data were collapsed across sex for presentation.

\subsubsection{Acoustic Startle during PPI Testing}

Relative to Homer $1 a^{+/+}$littermates, both Homer $1 a^{+/-}$and Homer $1 a^{-/-}$mice exhibited reduced startle responsiveness to the various acoustic stimuli (Figure 2A) [Genotype effect: $F(2,79)=21.95, p<0.0001$; Tone effect: $F(6,474)=84.60$, $p<0.0001$; Genotype $\times$ Tone: $F(12,474)=14.4, p<0.0001]$. Relative to controls, lower startle-responding to the $110 \mathrm{~dB}$ tone was observed in both Homer $1 a^{+/-}$and Homer $1 a^{-/-}$mice during the habituation phase (hab110), when it was presented alone (st110) or when it was preceded by either the 74 or the $90 \mathrm{~dB}$ pre-pulse ( $p$ 's $<0.007$; LSD post hoc tests). Moreover, both Homer $1 a^{+/-}$and Homer1a $a^{-/-}$mice exhibited lower spontaneous activity than Homerla $a^{+/+}$animals in the absence of any acoustic stimuli (st0; $p=0.006)$.

\subsubsection{PPI}

While the $74 \mathrm{~dB}$ pre-pulse failed to inhibit acoustic startle in any genotype $(p>0.25)$, a genotypic difference in PPI was observed in the presence of the $90 \mathrm{~dB}$ pre-pulse (Figure 2B) [Genotype effect: $F(2,79)=4.59, p=0.01]$. Further, a significant impairment in PPI was observed at the $90 \mathrm{~dB}$ prepulse in Homer1a-/mice, relative to controls $(p=0.003)$, with a modest impairment observed in Homer $1 a^{+/-}$mice $(p=0.09)$.

\subsubsection{Acoustic Acuity}

Although the tone-dependency of the startle response exhibited by Homer $1 a^{+/-}$and Homer1a $a^{-/-}$mice during PPI testing (Figure 2A) argued that Homerla deletion does not impair the ability to discriminate between certain acoustic stimuli, the unexpected blunting of the startle-responsiveness of the mutant mice prompted a test for a primary hearing deficit. For this, male Homer $1 a^{+/+}$, Homer $1 a^{+/-}$, and Homer $1 a^{-/-}$mice were randomly presented with acoustic stimuli ranging in intensity from 0 to $125 \mathrm{~dB}$. In this cohort, startle amplitude was also intensity-dependent (Figure 2C) [Tone effect: $F(8,152)=82.29$, $p<0.0001]$; however, although the results of the statistical 


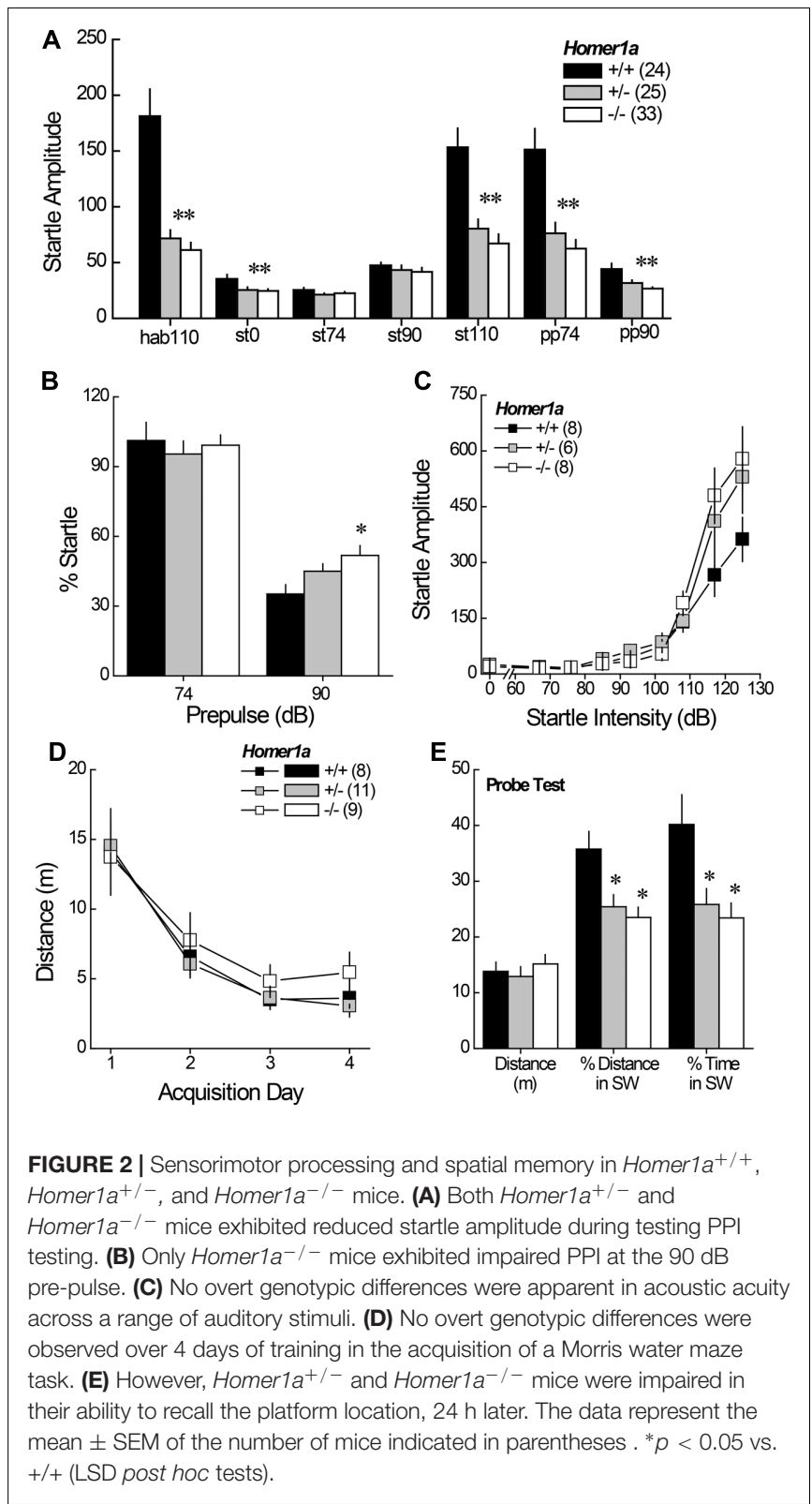

analyses indicated a significant interaction between genotype and tone $[F(8,152)=2.36, p=0.004]$, post hoc comparisons at each $\mathrm{dB}$ level failed to reveal genotypic differences in startle responsiveness.

\subsection{Spatial Learning and Memory}

Pan-Homer1 deletion markedly impairs learning and memory on several assays (Lominac et al., 2005; Szumlinski et al., 2005a; Gerstein et al., 2012) and intracranial manipulations of Homerla expression affect spatial memory (e.g., Klugmann et al., 2005; Celikel et al., 2007; Gerstein et al., 2012, p. 213). Thus, we trained male mice to locate a hidden platform in a Morris water maze task and then assessed for long-term spatial memory in a probe trial, conducted $24 \mathrm{~h}$ following the 4 th acquisition session. Surprisingly, genotypic differences in behavior were not detected during the acquisition phase of testing, either across trials within days, or across days of training (Figure 2D) [distance to locate platform, Trial effect: $F(3,225)=5.18, p=0.003$; Day effect: $F(3,225)=33.50, p<0.0001$; no main effect of, or interactions with the Genotype factor; data not shown for time taken to locate platform, Trial effect: $F(3,225)=7.87, p<0.0001$; Day effect: $F(3,225)=34.46, p<0.0001$; no main effect of, or interaction with, the Genotype factor]. In contrast to the data for maze acquisition, marked genotypic differences were observed regarding recall of the platform location, when tested 24 h later (Figure 2E), with both Homer1 $a^{+/-}$and Homer1a-/mice exhibiting impaired recall, as indicated by lower percent total distance and percent time spent in the SW quadrant, which formerly contained the hidden platform [for \% Distance: Genotype effect: $F(2,27)=6.79, p=0.004$; for \% Time: Genotype effect: $F(2,27)=5.82, p=0.008$; post hoc tests]. No genotypic difference in the distance swam (Figure 2E; $p=0.65$ ) argues that the recall impairment exhibited by Homerla mutants was unrelated to swimming ability.

\subsection{Cocaine-Conditioned Place-Preference}

Pan-Homer1 deletion increases sensitivity to the conditioned rewarding properties of cocaine (Szumlinski et al., 2004; Lominac et al., 2005). Thus, we characterized the dose-response function for cocaine-induced place-conditioning in male and female Homer $1 a^{+/+,+/-,-/-}$mice. No sex differences were observed for cocaine-induced place-conditioning [Side effect: $F(1,167)=223.67, p<0.000$; Dose $\times$ Side: $F(2,167)=11.36$, $p<0.0001$; Sex effect and interactions, $p$ 's $>0.10]$ and so, the data were collapsed across sex for presentation. Despite the large sample sizes employed in this experiment, we did not detect an effect of Homerla deletion upon the dose-response function for cocaine-induced place-preference (Figure 3; no Genotype effect or Genotype $\times$ Side interactions, $p$ 's $>0.35)$. These data argue little role for Homerla induction in either the associative learning/memory or incentive motivational processes involved in the development and expression of cocaine-conditioned reward.

\subsection{DHPG-Induced Glutamate Release}

Although it appeared as if Homerla deletion elevated baseline glutamate in the study of DHPG-induced glutamate release (Figure 4A; DHPG $=0 \mu \mathrm{M}$ ), the genotypic difference was not significant ( $t$-test: $p=0.19$ ). However, Homerla deletion prevented the capacity of DHPG to stimulate glutamate release within NAC (Figure 4A) [Genotype $\times$ Dose: $F(3,36)=26.02$, $p<0.0001]$. DHPG dose-dependently elevated glutamate in Homer $1 a^{+/+}$mice [DHPG effect: $F(3,15)=68.31, p<0.0001$ ], while no DHPG-induced rise was apparent in Homer1a-/mice (DHGP effect: $p=0.70$ ). In contrast to Homer1a deletion, a comparison of baseline glutamate indicated lower glutamate levels in Homer $1^{-/-}$versus Homer $1^{+/+}$mice $[t(16)=2.36$, $p=0.02]$. Further, pan-Homer1 deletion blunted, but did not block, the capacity of DHPG to increase NAC glutamate (Figure 4B) [Genotype $\times$ DHPG: $F(3,51)=4.65, p=0.006$ ], as evidenced by a significant DHPG-induced rise in glutamate in 


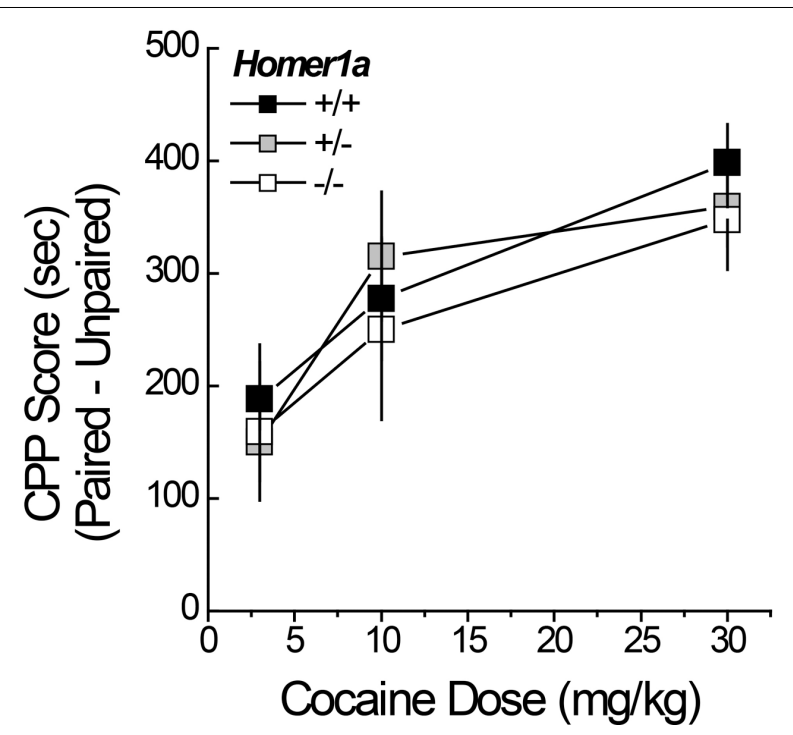

FIGURE 3 | Cocaine-induced place-conditioning in Homer1a $\mathrm{H}^{+/+}$, Homer1a ${ }^{+/-}$, and Homer1a-/- mice. When tested in a cocaine-free state, genotypic differences were not observed in the dose-response function for cocaine-induced place-preference exhibited by male and female mice. Occupancy difference $=$ time spent on the cocaine-paired minus -unpaired side in seconds). The data represent the mean \pm SEM of the number of mice indicated in parentheses.

both genotypes [DHPG effect, for Homer $1^{+/+}: F(3,24)=15.00$, $p<0.0001$; for Homer $\left.1^{-/-}: F(3,27)=4.37, p<0.01\right]$. These data provide evidence for distinct effects of Homer $1 \mathrm{a}$ and pan-Homer 1 deletion upon mGlu1/5-dependent regulation of extracellular glutamate in vivo.

\subsection{Depolarization-Induced NAC Glutamate and Dopamine Release}

In this study, both $\mathrm{Homerla}^{-/-}$(Figure 4C) and panHomer1 $^{-/-}$(Figure 4D) mice exhibited significantly lower baseline glutamate levels than their wild-type controls [for Homer1a: $t(13)=2.39, p=0.03$; for pan-Homer $1: t(14)=3.02$, $p=0.009]$. In contrast, Homer $1 a^{-/}-\mathrm{KO}$ mice exhibited a modest, but statistically significant elevation, in basal dopamine levels (Figure 4E) $[t(13)=2.05, p=0.045]$, whereas differences in basal dopamine were not apparent between Homer $1^{+/+}$and Homer $1^{-/}$mice (Figure 4F; $t$-test, $p>0.35$ ).

Despite employing the same perfusate through the course of study, the effects of depolarization were more pronounced in the Homerla versus the Homerl study, which might reflect differences in the genetic background of the two mutant lines. Nevertheless, a marked genotypic difference in $\mathrm{K}^{+}$-stimulated glutamate release was apparent in the study of Homerla mice [Genotype $\times \mathrm{K}^{+}: F(2,26)=7.93, p=0.002$ ]; while, $\mathrm{K}^{+}$ stimulated a rise in glutamate in both genotypes (Figure $4 \mathrm{C}$ ) $\left[\right.$ for Homer $1 a^{+/+}: F(2,14)=10.70, p=0.002$; for Homer $1 a^{-/-}$: $F(2,12)=6.01, p=0.02]$, the magnitude of the rise observed in Homer $1 a^{-/-}$animals was considerably less than that observed in their controls. Although, Homer $1^{-/-}$mice exhibited lower
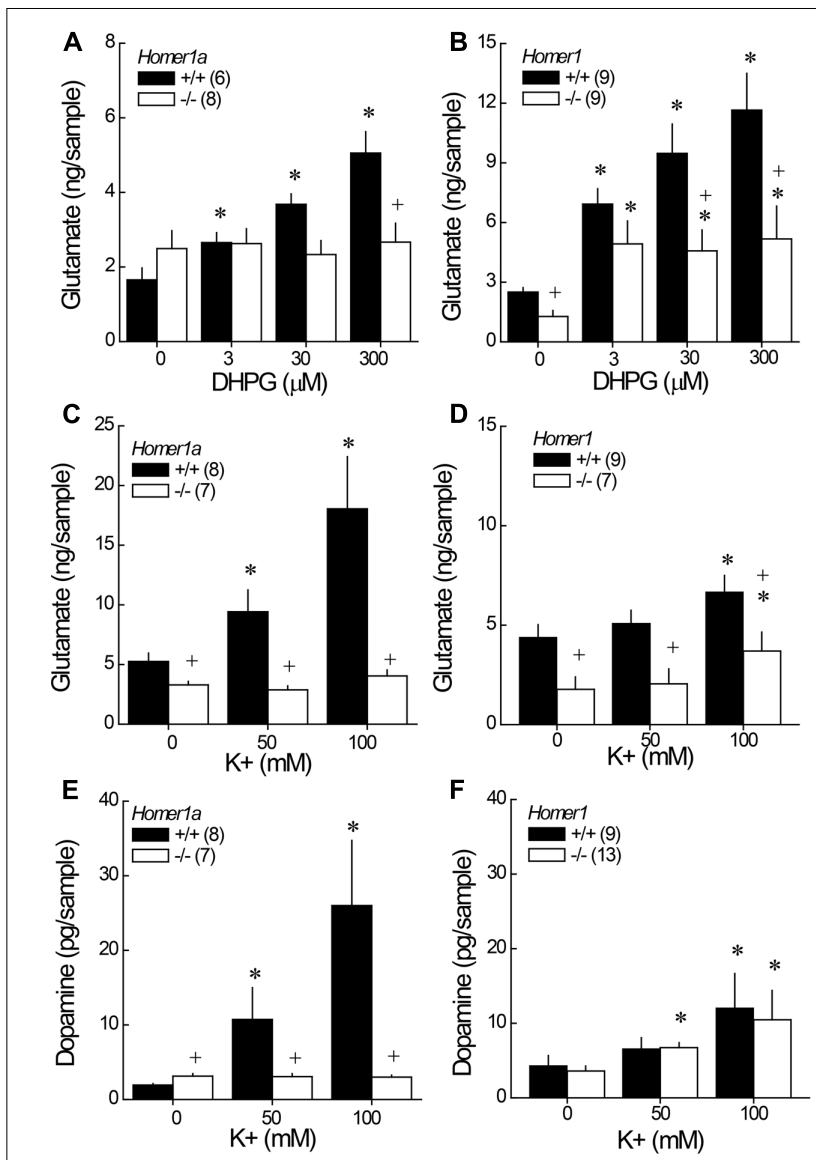

FIGURE 4 | Comparison of the effects of Homer1a versus pan-Homer1 deletion upon the regulation of NAC glutamate and dopamine. Intra-NAC perfusion with increasing concentrations of the mGlu1/5 agonist DHPG failed to increase extracellular glutamate in Homer1a-/- mice (A), while Homer1 $^{-/-}$mice exhibited a moderate, but significant, DHPG-stimulated rise in NAC glutamate (B). Intra-NAC perfusion with high $\mathrm{K}^{+}$solutions elevated NAC glutamate levels and this effect was markedly blunted in Homer1a-/mice (C), but not in Homer1-/- mice, although Homer1-/- mice exhibited lower glutamate levels, overall (D). Homer1a-/- mice failed to exhibit $\mathrm{K}^{+}$-stimulated dopamine release $(\mathbf{E})$, while dopamine release was unaffected in Homer1-/- mice (F). The data represent the mean \pm SEM of the number of mice indicated in parentheses. ${ }^{*} p<0.05$ vs. $0 \mu \mathrm{M} ;+p<0.05$ vs. Homer1at/+ or Homer1+/+.

glutamate levels than Homer ${ }^{+/+}$animals, irrespective of the concentration of $\mathrm{K}^{+}$perfused (Figure 4D) [Genotype effect: $F(1,14)=9.67, p=0.008]$, Homer1 deletion did not alter the capacity of $\mathrm{K}^{+}$to stimulate glutamate release within the $\mathrm{NAC}\left[\mathrm{K}^{+}\right.$ effect: $F(2,28)=13.08, p<0.0001$; Genotype $\left.\times \mathrm{K}^{+}: p=0.11\right]$.

In the case of dopamine, Homerla deletion prevented $\mathrm{K}^{+}$stimulated dopamine release within the NAC (Figure 4E) [Genotype $\times \mathrm{K}^{+}: F(2,38)=4.57, p=0.02$; one-way ANOVAs: for Homerla $a^{+/}, F(2,26)=9.32, p=0.001$; for Homer1a ${ }^{-/-}$: $p=0.78]$. In contrast, pan-Homer1 deletion had no impact upon $\mathrm{K}^{+}$-stimulated dopamine release in this region $\left[\mathrm{K}^{+}\right.$effect: $F(2,40)=6.86, p=0.003$; Genotype effect and interaction, $p$ 's $>0.70]$. These data provide novel evidence that the selective deletion of Homer1a, but not the entire Homer1 gene, reduces 

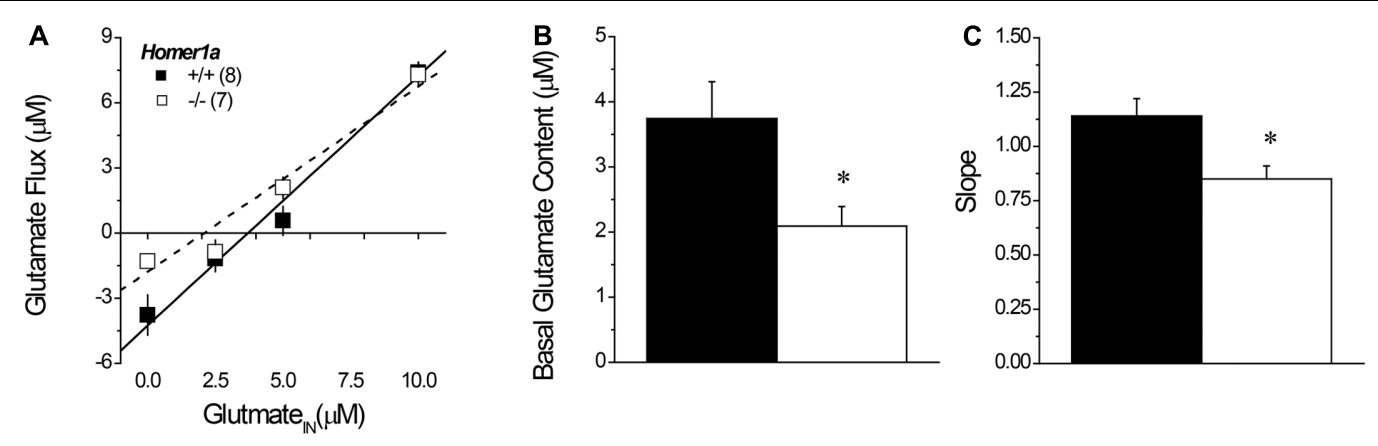

FIGURE 5 | Basal extracellular glutamate content and release/clearance in Homer1 $a^{+/+}$and Homer1a ${ }^{-/-}$mice. Summary of the results of the linear regression analyses of the data from the no net-flux study of extracellular glutamate (A), highlighting (B) the lower X-intercept (an estimate of basal glutamate content) and (C) reduced slope (an index of reuptake/release) in Homer1 ${ }^{-/-}$versus Homer1 ${ }^{+/+}$animals. The data represent the mean $\pm \mathrm{SEM}$ of the number of mice indicated in parentheses in (A). * $p<0.05$ vs. $+/+$.

the excitability of both dopamine and glutamate terminals within the NAC.

\subsection{Glutamate No Net-Flux}

Linear regression analyses of the plots of the no net-flux study (Figure 5A) confirmed lower NAC extracellular glutamate content in Homer1a $a^{-/-}$versus Homer1a $a^{+/+}$mice (Figure 5B) $[t(13)=5.85, p=0.03]$. Linear analysis also indicated a significant reduction in the in vivo recovery of glutamate in Homer $1 a^{-/-}$mice relative to Homer $1 a^{+/+}$controls, as indicated by differences in the slopes of the linear regressions (Figure 5C) $[t(13)=5.51, p=0.04]$.

\subsection{AAV-Homer1a Effects upon Genotypic Differences in Behavior in Drug-Naïve Animals}

To examine an active role for nucleus accumbens Homerla in the behavioral phenotype of Homer $1 a^{-/-}$mice, AAV constructs carrying either Homer1a cDNA (AAV-Homer1a) or a scrambled DNA control were infused into the nucleus accumbens of Homerla $a^{+/+}$and Homerla $a^{-/-}$mice.

\subsubsection{Acoustic Startle and PPI}

We first employed Tukey tests for planned comparisons to compare between Homerla $a^{+/+}$and Homerla $a^{-/-}$mice infused with the control AVV to confirm replication of our prior genotypic difference in startle amplitude. Indeed, we replicated lower startle responsiveness in Homer $1 a^{-/-}$mice, specifically during habituation to the $110 \mathrm{~dB}$ stimulus $(p=0.04)$, in response to the $90 \mathrm{~dB}$ tone $(p=0.02)$, the $110 \mathrm{~dB}$ tone $(p=0.04)$ and in response to the $110 \mathrm{~dB}$ tone when preceded by the 74 or the $90 \mathrm{~dB}$ prepulse (both $p$ 's $=0.05$ ). We did not observe a genotypic difference between AAV-controls at the 0 or $74 \mathrm{~dB}$ stimuli or when the $110 \mathrm{~dB}$ stimulation was preceded by the $90 \mathrm{~dB}$ prepulse ( $p$ 's $>0.90$ ). Planned comparisons were then conducted between AAV-control- and AAV-Homerla-infused animals within each genotype. Despite what appeared to be a relatively selective effect of Homerla over-expression upon the startle responsiveness of Homer1 $a^{-/-}$mice (Figure 6A), this statistical approach yielded

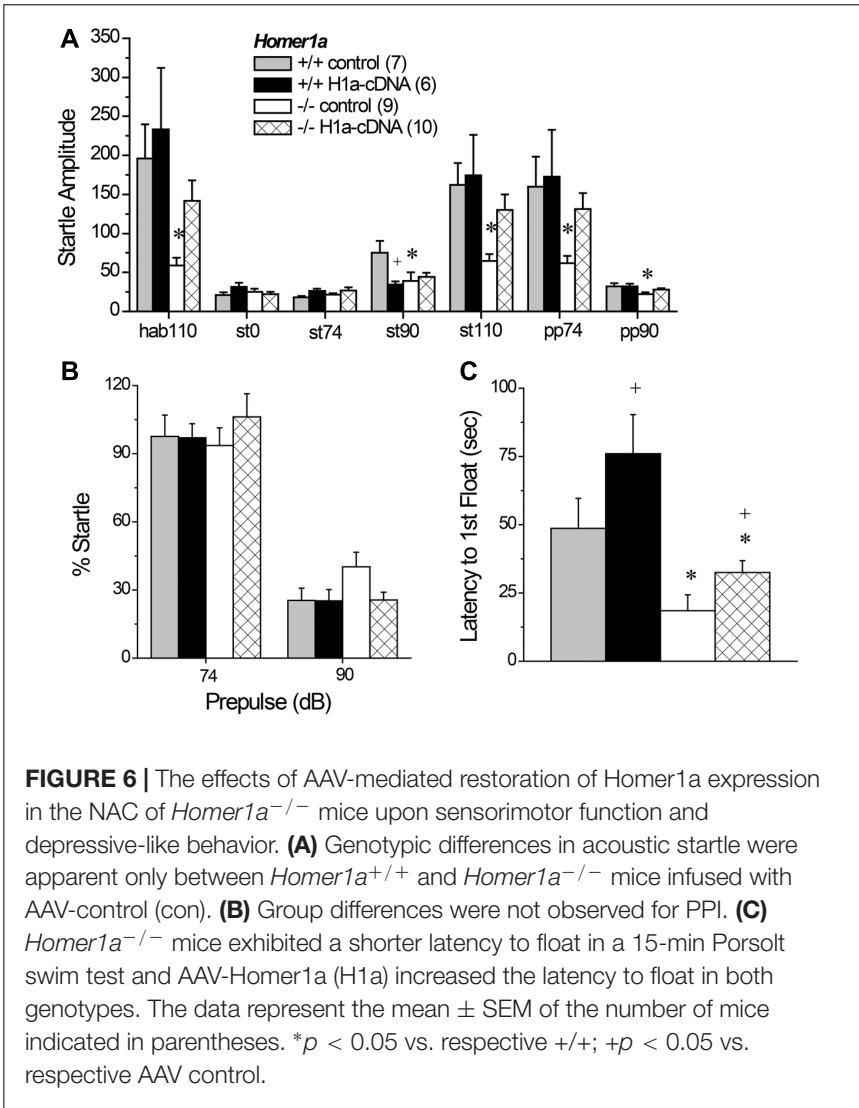

no AAV-Homerla effects in either genotype at any of the stimulus intensities $(p$ 's $>0.20)$, with the exception of a significant reduction in the response exhibited by Homer $1 a^{+/+}$mice to the $90 \mathrm{~dB}$ tone ( $p=0.02$; st90 in Figure 6A). However, a comparison of the startle amplitude exhibited between Homer $1 a^{+/+}$and Homer1a- $a^{-1}$ mice infused intra-NAC with AAV-Homerla indicated no significant genotypic differences at any of the stimulus intensities ( $p$ 's $>0.40$ ), arguing that AAV-Homer1a infusion into the NAC was sufficient to reverse the blunted sensorimotor-processing induced by Homerla deletion. 
A comparable analysis of PPI (Figure 6B) detected no group differences at the $74 \mathrm{~dB}$ prepulse (for all comparisons, $p$ 's $>0.70$ ) or at the $110 \mathrm{~dB}$ prepulse (for all comparisons, $p$ 's $>0.10$ ). Thus, we failed to replicate the PPI deficit observed in AAV-naïve mice (Figure 2B), nor did we find evidence to support an active role for NAC Homerla in regulating the magnitude of PPI.

\subsubsection{Porsolt Swim Test}

Replicating the data in Figure 1E, Homer1a deletion reduced the latency to first exhibit floating [Genotype effect: $F(1,29)=15.93$, $p<0.0001]$; however, intra-NAC AAV-Homerla infusion increased the latency first float, irrespective of genotype (Figure 6C) $[\mathrm{AAV}$ effect; $F(1,29)=5.00, p=0.03$; interaction: $p=0.48$, with AAV-Homerla partially reversing the behavior of Homer $1^{-/-}$mice. In contrast, we did not replicate the genotypic difference in total floating nor did we observed any AAV effect upon total floating in this experiment (data not shown; Genotype $\times$ AAV ANOVA, all $p$ 's $>0.35$ ). Further, AAV infusion did not impact the distance traveled during swim testing (data now shown; Genotype $\times$ AAV ANOVA, all $p$ 's $>0.55$ ).

\subsection{AAV-Homer1a Effects upon Genotypic Differences in Cocaine-Induced Behavior}

Although we failed to detect an effect of Homerla deletion upon cocaine-conditioned reward (Figure 3), Homerla deletion prevents the development of cocaine-induced behavioral sensitization (Park et al., 2013) and the effect of Homerla overexpression within the NAC is not known. Thus, we employed our cocaine-induced place-conditioning procedures to determine the effects of intra-NAC AAV-Homerla infusion upon spontaneous and cocaine-induced changes in locomotor activity, as well as place-conditioning, in Homer $1 a^{+/+}$and Homer1 $1 a^{-/-}$mice.

\subsubsection{Locomotor Reactivity to Novelty and Habituation}

A significant Genotype by AAV interaction was observed for the locomotor hyperactivity expressed when mice were allowed to explore the place-conditioning apparatus on the PreTest (Figure 7A) [Genotype $\times$ AAV: $F(1,31)=4.45, p=0.04$ ] . This interaction reflected genotypic differences between Homerla $^{+/+}$ and Homer1 $a^{-/-}$mice infused with AAV-control $(p=0.02)$, which was not apparent in mice infused with AAV-Homerla $(p=0.70)$. When compared to their respective AAV-control, there was no detectable effect of AAV-Homerla upon the novelty-induced locomotion of either Homerla $a^{+/+}(p=0.12)$ or Homer1 $a^{-/-}$mice $(p=0.18)$. No group differences were observed with respect to either the locomotor response to an acute saline injection (Genotype $\times$ AAV ANOVA, all $p$ 's $>0.65)$ or the change in saline-induced locomotion across the four saline-conditioning sessions (data not shown) [Saline Injection effect: $F(3,84)=4.69, p=0.04$; all other p's > 0.07].

\subsubsection{Cocaine-Induced Locomotion and Sensitization}

Interestingly, the group differences in the acute locomotor response to an acute injection of $30 \mathrm{mg} / \mathrm{kg}$ cocaine was inverse
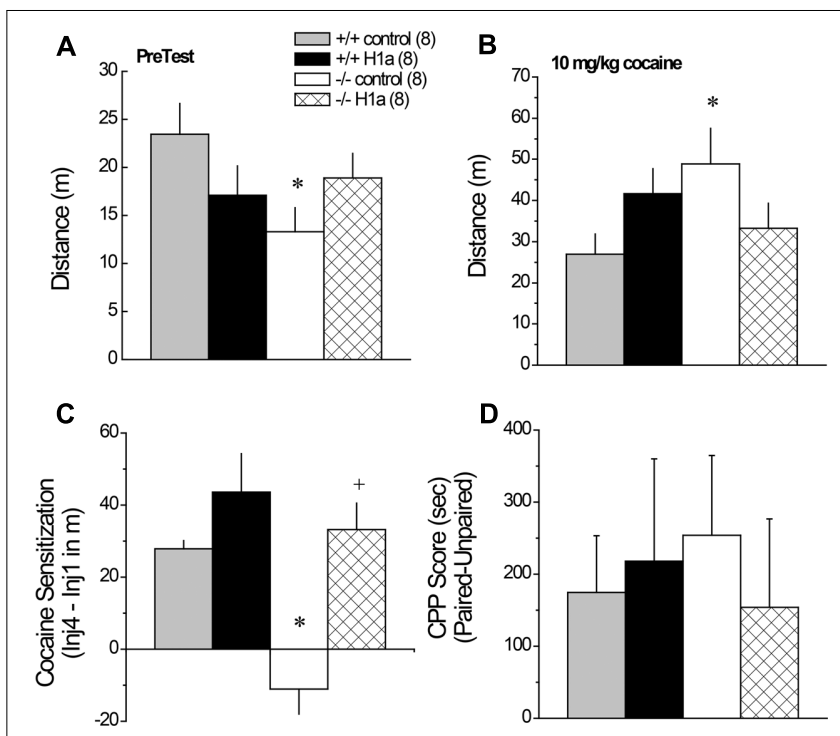

FIGURE 7 | The effects of AAV-mediated restoration of Homer1a expression in the NAC of Homer1a-/- mice upon behavior in a cocaine-conditioned place-preference assay. Genotypic differences were observed only in mice infused with AAV-control for both the total distance traveled during the 15-min PreTest (A) and the distance traveled in response to an acute injection of $10 \mathrm{mg} / \mathrm{kg}$ cocaine (B). (C) Homer1 $\mathrm{a}^{-/-}$controls failed to exhibit cocaine-induced sensitization and this phenotype was reversed by AAV-Homer1a infusion. (D) Group differences were not observed for the magnitude of a conditioned place-preference elicited by four pairings of $10 \mathrm{mg} / \mathrm{kg}$ cocaine. The data represent the mean \pm SEM of the number of mice indicated in parentheses. ${ }^{*} p<0.05$ vs. respective $+/+;+p<0.05$ vs. respective AAV control.

of that observed for novelty-induced locomotion (Figure 7A vs. 7B) [Genotype $\times$ AAV: $F(1,28)=5.30, p=0.03$ ], with significant genotypic differences observed between Homer1a $a^{+/+}$ and Homer1 $a^{-/}$mice infused with AAV-control $(p=0.03)$, but not mice infused with AAV-Homerla $(p=0.38)$. Further, we observed no effect of AAV-Homerla upon acute cocaine-induced locomotion in either Homerla $a^{+/+}(p=0.13)$ or Homer1a $a^{-/-}$ mice $(p=0.11)$.

In contrast to the locomotor response to acute cocaine, AAV-Homerla infusion completely reversed the effects of Homer1a deletion upon the development of cocaine-induced locomotor sensitization [Genotype $\times \mathrm{AAV} \times$ Cocaine Injection: $F(3,84)=4.94, p=0.003]$. Consistent with prior results for AAV-naïve mice (Park et al., 2013), Homerla ${ }^{+/+}$mice infused with AAV-control exhibited robust sensitization across the four cocaine injections $[F(3,21)=15.23, p<0.0001]$, as did Homer1a $a^{+/+}$mice infused with AAV-Homerla $[F(3,21)=12.37$, $p<0.0001]$. While cocaine-induced locomotion did vary as a function of repeated cocaine treatment in Homer1 $a^{-/-}$infused with AAV-control $[F(3,21)=4.33, p=0.02]$, this reflected a decline, rather than an increase, in activity with repeated cocaine treatment. In contrast, Homerla $a^{-/-}$mice infused with AAVHomerla exhibited an injection-dependent increase in cocaineinduced locomotion $[F(3,21)=8.36, p=0.001]$, indicative of restored sensitization. 
To facilitate visualization of the group differences in cocaineinduced sensitization, the data are presented as difference in locomotor activity from injection 1 to 4 of repeated treatment (Figure 7C). Analysis of these data further indicates a reversal of the cocaine-sensitization phenotype of Homer1a ${ }^{-/-}$mice [Genotype $\times$ AAV: $F(1,31)=4.21, p=0.05]$, with Homer1a ${ }^{-/-}$ AAV-control exhibiting a locomotor phenotype distinct from the other groups tested ( $p$ 's $\leq 0.001$ ). Although AAV-Homer1a infusion increased the magnitude of the cocaine-sensitized response in both genotypes, the AAV effect was significant only in Homer1a $a^{-/-}$mice (Homer1a $a^{+/+}: p>0.20$; Homer1a $a^{-/-}$: $p<0.0001)$.

\subsubsection{Cocaine-Conditioned Place-Preference}

Relative to their sensitized locomotor response to cocaine (Figure 7C), the magnitude of a cocaine-conditioned placepreference was highly variable (Figure 7D) and we detected no effect of genotype or AAV treatment upon the CPP Score exhibited by the mice when tested for compartment preference in a cocaine-free state (Figure 8D; Genotype $\times$ AAV ANOVA on CPP Score, $p$ 's $>0.45$ ).

\subsection{AAV-Homer1a Effects on Basal and Cocaine-Stimulated Neurotransmission}

\subsubsection{Cocaine-Induced Glutamate Sensitization}

An analysis of the average baseline glutamate levels obtained using conventional in vivo microdialysis procedures failed to detect any group differences (data not shown; Genotype $\times$ AAV $\times$ Injection Number ANOVA, $p$ 's $>0.15)$. As expected, the capacity of cocaine to increase NAC glutamate was injection-dependent [Injection Number effect: $F(1,67)=16.04$, $p<0.0001]$. However, the magnitude of the cocainesensitized glutamate response varied as a function of both genotype and AAV treatment [Genotype $\times \mathrm{AAV} \times$ Injection Number: $F(1,67)=8.36, p=0.005]$. Neither genotype nor AAV infusion influenced the glutamate response to acute cocaine (Genotype $\times$ AAV ANOVA: all $p$ 's > 0.45), while AAV-Homerla infusion augmented the capacity of the 6th cocaine injection to increase glutamate response only in Homer1 $a^{-/-}$mice [Genotype $\times$AAV: $F(1,32)=-10.58$, $p=0.003]$. Indeed, all groups but the Homerla ${ }^{-/-}$ controls exhibited greater cocaine-induced glutamate release on the 6 th versus the 1st cocaine injection (for Homer1 $a^{-/-}$AAV-control: $p=0.23$; for all other groups, p's < 0.04).

\subsubsection{Cocaine-Induced Dopamine Sensitization}

As observed for glutamate, there were no group differences in baseline levels of dopamine (data not shown; Genotype $\times$ AAV $\times$ Injection Number ANOVA, all $p$ 's $>0.06$ ) and repeated cocaine treatment elicited a robust increase in dopamine that varied as a function of Genotype [Injection Number effect: $F(1,67)=21.76, p<0.0001$; Genotype $\times$ Injection Number: $F(1,67)=9.00, p=0.004]$, but not AAV infusion (AAV $\times$ Injection Number: $p=0.15)$. Although the magnitude of the dopamine response to cocaine was greater following repeated treatment, the effects of
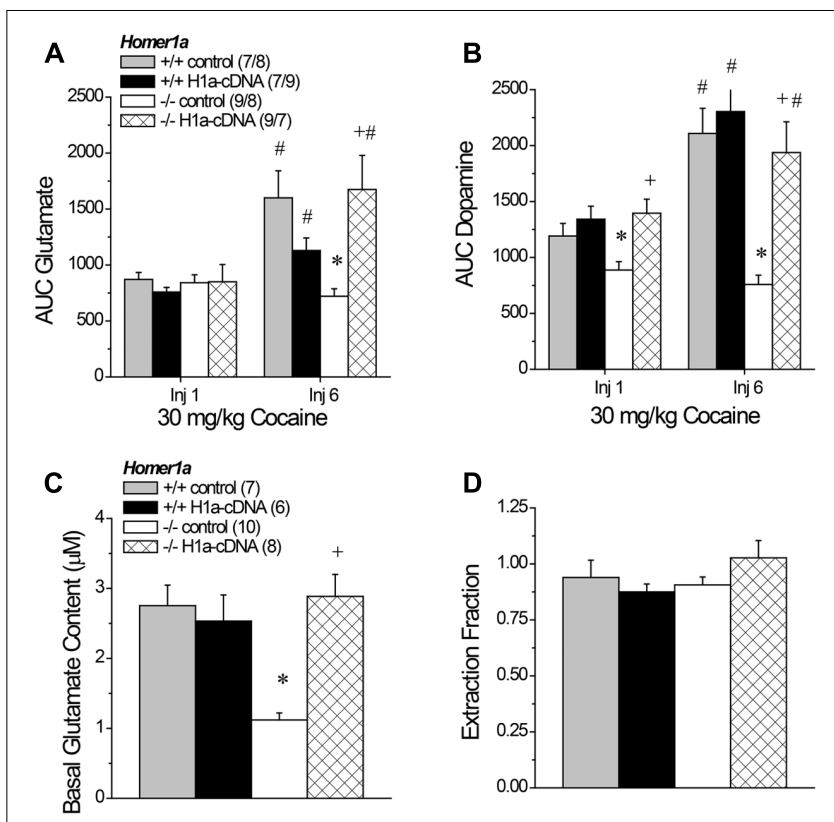

\section{E}
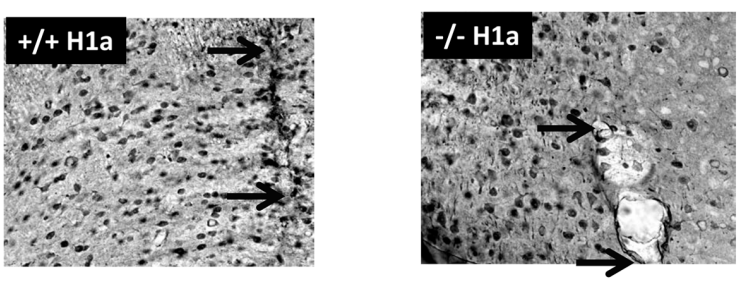

FIGURE 8 | The effects of AAV-mediated restoration of Homer1a expression in Homer1a-/- mice upon basal and cocaine-stimulated neurotransmission. (A) Under conventional in vivo microdialysis procedures, repeated treatment with $30 \mathrm{mg} / \mathrm{kg}$ cocaine sensitized cocaine-induced glutamate release in both Homer1a+/+ infused intra-NAC with AAV, but only in Homer1a- ${ }^{-1}$ mice infused with AAV-Homer1a (H1a). (B) Intra-NAC AAV-Homer1a infusion increased the magnitude of the cocaine-elicited rise in dopamine in Homer1a $^{-/-}$mice and facilitated the expression of dopamine sensitization with repeated cocaine treatment. The sample sizes in (B) are presented in (A). When determined using glutamate no net-flux procedures, intra-NAC AAV-Homer1a reversed the low basal glutamate phenotype of Homer1a- /mice (C), but did not alter the slope of linear regressions in either genotype (D). The samples sizes in (D) are presented in (C). The data in (A-D) represent the mean \pm SEM of the number of mice indicated in parentheses. ${ }^{*} p<0.05$ vs. respective $+/+;+p<0.05$ vs. respective AAV control; $\# p<0.05$ vs. Injection 1 (sensitization). (E) Representative images of $\mathrm{HA}$-staining within the NAC of Homer1a ${ }^{+/+}$(left) and Homer1a-/- mice (right) infused with AAV-Homer1a (20X magnification), illustrating comparable neuronal transduction around the site of microinjection/microdialysis probe insertion. Arrows in $\mathbf{( E )}$ represent the extent of the microdialysis probe membranes.

AAV infusion upon the genotypic differences in dopamine responsiveness were similar across the microdialysis sessions (Figure 8B) [Genotype $\times$ AAV: $F(1,67)=7.46, p=0.008$; threeway interaction: $p=0.21$, with Homer $1 a^{-/-}$controls exhibiting a blunted dopamine response to cocaine, relative to their Homer $1^{+/+}$counterparts (p) and AAV-Homerla augmenting the cocaine-induced rise in dopamine only in Homerla ${ }^{-/-}$ animals (for Homer1 $a^{+/+}: p=0.57$; Homer1 $a^{-/-}: p<0.0001$ ). 


\subsubsection{No Net-Flux Glutamate}

A planned comparison of the genotypic difference in the $\mathrm{x}$-intercept for mice infused with $\mathrm{AAV}$-control replicated lower basal glutamate content in Homer1a $a^{-/}$mice $(p<0.0001)$. We also detected a significant Genotype $\times$ AAV interaction for the $\mathrm{x}$-intercept (Figure 8C) $[F(1,30)=14.08, p=0.001]$ that reflected an AAV-Homerla-induced increase in basal glutamate content in Homer1a-/- $(p<0.0001)$, but not in Homer $1 a^{+/+}$animals $(p=0.65)$. A comparable analysis of the slope of the linear regressions indicated that we did not replicate the genotypic difference in the extraction fraction in AAV-controls (Figure 8D; $p=0.67$ ). Further, we did not observe any effect of AAV infusion upon this measure of glutamate release/reuptake in the NAC (Genotype $\times$ AAV: all $p$ 's $>0.10)$. Thus, Homerla actively regulates basal extracellular glutamate content with in the NAC without influencing release/reuptake.

\section{DISCUSSION}

The induction of the IEG Homer isoform Homerla is theorized to play a critical role in synaptic rearrangement and neuroplasticity relevant to various cognitive and behavioral processes, as well as pathophysiology in mental disease (cf. Shiraishi-Yamaguchi and Furuichi, 2007; Szumlinski et al., 2008a; Fagni, 2012; Marton et al., 2015). Despite its initial characterization over 20 years ago (Brakeman et al., 1997; Kato et al., 1998), we still know relatively little regarding the functional relevance of Homerla induction in vivo. Herein, we employed an AAV strategy and extend prior results for Homerla $a^{-/}$mice (Park et al., 2013) by demonstrating that Homerla within the NAC actively regulates cocaineinduced behavior, glutamate and dopamine sensitization, as well as basal extracellular glutamate levels in this region. Moreover, we demonstrate that NAC Homerla expression actively regulates sensorimotor processing and sensorimotorgating. We show also that Homerla induction is necessary for normal recall of spatial memory and serves to inhibit depressive-like behavior in certain behavioral paradigms, but is not required to manifest anxiety-like behavior or cocaineconditioned reward. Lastly, we demonstrate the importance of Homerla induction for mGlu1/5 function within the NAC, as well as the excitability of both glutamate and dopamine terminals therein, and provide novel in vivo evidence that the NAC neurochemical phenotype produced by Homer1a deletion is distinct from that produced by deletion of the entire Homer1 gene.

Our current knowledge concerning the behavioral relevance of distinct Homer1 isoforms can be derived from a relatively short-list of behavioral phenotyping studies of: pan-Homer1 ${ }^{-/-}$ mice (Szumlinski et al., 2004, 2005a; Lominac et al., 2005; Jaubert et al., 2007; Gerstein et al., 2012; Wagner et al., 2014, 2015), transgenic mice over-expressing Homerla within the striatum (Tappe and Kuner, 2006) and transgenic mice incapable of Homerla induction (Inoue et al., 2009; Park et al., 2013; present study). This line of interrogation is complemented and augmented by a number of reports describing the effects of site-specific manipulations of different Homer1 isoforms in the brain of wild-type rodents, as well as Homer-related mutants (Ghasemzadeh et al., 2003; Klugmann et al., 2005; Lominac et al., 2005; Szumlinski et al., 2006; Ary et al., 2013; Gerstein et al., 2013; Wagner et al., 2013, 2014, 2015; Banerjee et al., 2016; Figure 7). However marked procedural variations across these studies render it difficult to compare outcomes directly. This being said, the behavioral testing procedures employed in the present study of Homerla $a^{-/}$mice were highly comparable, and sometimes identical, to those used in our earlier behavioral characterization of pan-Homer1-/- mice (Szumlinski et al., 2004, 2005a; Lominac et al., 2005), facilitating interpretation of disparities and similarities in behavioral phenotypes across the two mutant lines. A side-by-side comparison of the effects of Homerla versus pan-Homer1 deletion upon spontaneous behaviors is provided in Table 1. As is apparent from this table and the extant literature, pan-Homer $1^{-/}$mice exhibit robust and complex behavioral anomalies (Szumlinski et al., 2004, 2005a; Lominac et al., 2005; Jaubert et al., 2007; Gerstein et al., 2012; Wagner et al., 2013, 2014, 2015). In contrast, the behavioral phenotype of Homerla $a^{-/-}$mice is surprisingly similar to their wild-type controls in a variety of assays (Inoue et al., 2009; Park et al., 2013, Table 1), although some behavioral anomalies were observed in the present study that are discussed below.

\subsection{Preventing Homer1a Induction Produces an Affective Phenotype That Is Distinct from That Produced by Homer1 Deletion}

Pan-Homer $1^{-/-}$mice exhibit hyper-emotionality across a variety of paradigms (Szumlinski et al., 2004, 2005a; Jaubert et al., 2007; Wagner et al., 2014, 2015). In stark contrast, the anxiety-like behavior exhibited by Homer $1 a^{-/-}$herein was indistinguishable from that of wild-type mice, although Homer $1^{+/-}$mutants did exhibit signs of hypo-anxiety on the elevated plus maze (Figures 1A,B). The present results are in line with the results of a study by Inoue et al. (2009), in which the Homerla deletion did not alter anxiety-like behavior on the elevated plus-maze, open field or light-dark box tests (Inoue et al., 2009). These data for Homerla-null mutants are interesting in light of evidence that transgenic mice over-expressing Homerla within striatum increases anxiety signs in mice, which could be reversed upon conditional deletion of Homer1a (Tappe and Kuner, 2006). Taken together, the above findings from constitutive mutant mice argue that Homerla over-expression is sufficient, but not necessary, for the manifestation of anxiety-like behavior.

However, other data in the literature argue that Homerla induction exerts an "anxiolytic" or "anti-depressant" effect. For example, AAV-mediated Homerla over-expression within the basolateral amygdala reduces the manifestation of fearconditioning, as well as social interaction (Banerjee et al., 2016), while AAV-mediated restoration of Homerla to the prefrontal cortex of pan-Homer $1^{-/-}$mice reverses their hyper-anxious and depressive-like phenotype (Lominac et al., 2005). Consistent 
TABLE 1 | Comparison of the behavioral phenotypes observed in Homer1a-/- versus pan-Homer1-/- mice.

\begin{tabular}{|c|c|c|c|}
\hline Paradigm & Dependent variable & Homer1a $^{-/-}$ & Pan-Homer1-/- \\
\hline \multicolumn{4}{|l|}{ Anxiety-like behavior: } \\
\hline \multirow[t]{2}{*}{ Elevated plus-maze } & Open arm entries & $\mathrm{WT}=\mathrm{KO}$ Section 3.1 .1 & $\mathrm{WT}=\mathrm{KO}^{1}$ \\
\hline & Open arm time & $\mathrm{WT}=\mathrm{KO}$ Section 3.1.1 & $\mathrm{WT}=\mathrm{KO}^{1}$ \\
\hline \multirow[t]{3}{*}{ Novel object test } & Latency to contact & $\mathrm{WT}=\mathrm{KO}$ Section 3.1 .2 & \\
\hline & No. Ccontacts & $\mathrm{WT}=\mathrm{KO}$ Section 3.1 .2 & $\mathrm{WT}>\mathrm{KO}^{2}$ \\
\hline & Time in contact & $\mathrm{WT}=\mathrm{KO}$ Section 3.1 .2 & $\mathrm{WT}>\mathrm{KO}^{2}$ \\
\hline \multirow[t]{3}{*}{ Novel environment test } & Distance & $\mathrm{WT}=\mathrm{KO}$ Section 3.1 .4 & $\mathrm{WT} \leq \mathrm{KO}^{2,3}$ \\
\hline & Latency to center & $\mathrm{WT}=\mathrm{KO}$ Section 3.1 .4 & \\
\hline & Center entries & $\mathrm{WT}=\mathrm{KO}$ Section 3.1 .4 & \\
\hline \multirow[t]{3}{*}{ Habituation to Nnovel Eenvironment } & Distance & $\mathrm{WT}=\mathrm{KO}$ Section 3.1 .4 & $\mathrm{WT}>\mathrm{KO}^{2,3}$ \\
\hline & Latency to center & $\mathrm{WT}=\mathrm{KO}$ Section 3.1 .4 & \\
\hline & Center entries & $\mathrm{WT}=\mathrm{KO}$ Section 3.1 .4 & \\
\hline \multicolumn{4}{|l|}{ Depressive-like behavior: } \\
\hline \multirow[t]{2}{*}{ Porsolt swim test } & Latency to float & $\mathrm{WT}>\mathrm{KO}$ Section 3.1 .3 & $\mathrm{WT}>\mathrm{KO}^{2,3}$ \\
\hline & No. floats & $\mathrm{WT}=\mathrm{KO}$ Section 3.1 .3 & $\mathrm{WT}>\mathrm{KO}^{2,3}$ \\
\hline \multicolumn{4}{|l|}{ Learning and memory: } \\
\hline \multirow[t]{3}{*}{ Morris water maze } & Training: latency to platform & $\mathrm{WT}=\mathrm{KO}$ Section 3.3 & $\mathrm{WT}<\mathrm{KO}^{1}$ \\
\hline & Training: distance to platform & $\mathrm{WT}=\mathrm{KO}$ Section 3.3 & $\mathrm{WT}<\mathrm{KO}^{1}$ \\
\hline & Test: time in quadrant & $\mathrm{WT}>\mathrm{KO}$ Section 3.3 & 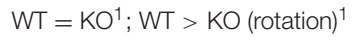 \\
\hline \multicolumn{4}{|l|}{ Sensorimotor processing: } \\
\hline \multirow[t]{2}{*}{ Acoustic startle } & Basal startle (0 dB) & $\mathrm{WT}>\mathrm{KO}$ Section 3.2 .1 & $\mathrm{WT}=\mathrm{KO}^{1-3}$ \\
\hline & Startle amplitude w/o prepulse & $\mathrm{WT}>\mathrm{KO}$ Section 3.2.1 $; \mathrm{WT}=\mathrm{KO}$ Section 3.2.3 & $\mathrm{WT}=\mathrm{KO}^{1-3}$ \\
\hline \multirow[t]{2}{*}{ PPI } & $74 \mathrm{~dB}$ prepulse & $\mathrm{WT}=\mathrm{KO}$ Section 3.2.2 & $\mathrm{WT}=\mathrm{KO}^{1-3}$ \\
\hline & $90 \mathrm{~dB}$ prepulse & $\mathrm{WT}>\mathrm{KO}$ Section 3.2 .2 & $\mathrm{WT}=\mathrm{KO}^{1-3}$ \\
\hline
\end{tabular}

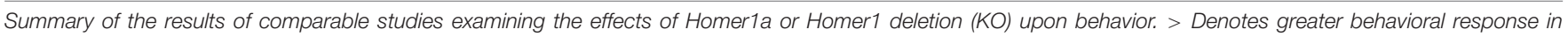

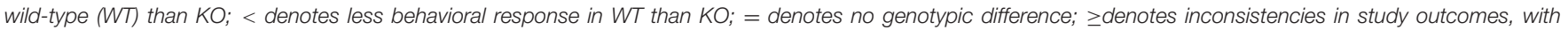

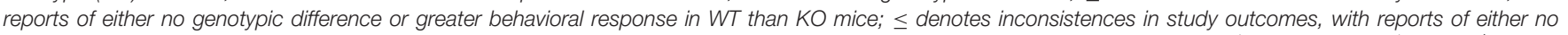

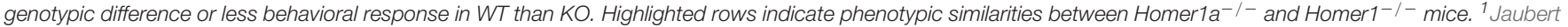
et al. (2007); ${ }^{2}$ Szumlinski et al. (2005a); ${ }^{3}$ Lominac et al. (2005); ${ }^{4}$ Park et al. (2013).

with these latter data, both Homer1a+/- and Homer1a $a^{-/-}$ mice exhibited a reduced latency to float in the Porsolt swim test in the present study (Figure 1E). In fact, this particular response to a stressor was the only emotion-related phenotype expressed in common by Homer1a $a^{-/-}$and pan-Homer1 ${ }^{-/-}$ mice (see Table 1). Moreover, AAV-mediated Homerla overexpression within the NAC increased the float latency in both Homerla $^{+/+}$and Homerla ${ }^{-/-}$mice (Figure 6C), arguing that Homerla induction within both the cell body and terminal regions of the corticoaccumbens projections actively gates a depressive-like phenotype - a finding in line with associations between variants in the Homer1 gene and major depressive disorder (e.g., Rietschel et al., 2010; Strauss et al., 2012; Rao et al., 2017). However, it is noteworthy that Homerla deletion did not produce a "pro-depressive" effect in our saccharin preference test. In fact, a review of the extant literature suggests that site-specific Homerla manipulations induce more robust and consistent effects upon negative affect (Lominac et al., 2005; Tappe and Kuner, 2006; Banerjee et al., 2016) than Homerla deletion (Inoue et al., 2009; Figure $\mathbf{1}$ and Table 1). This raises the possibility that Homerla induction within distinct brain regions may exert opposing roles in regulating affective responding that are masked under constitutive inhibition of IEG induction.

\subsection{Prevention of Homer1a Induction Produces a Cognitive Phenotype That Is Distinct from That Produced by Homer1 Deletion}

Homer1a induction is theorized to facilitate the rearrangement of the synaptic architecture of excitatory glutamate synapses necessary for metaplasticity and learning (e.g., $\mathrm{Hu}$ et al., 2010; Fagni, 2012; Marton et al., 2015). Although associative learning is intact in pan-Homer1 ${ }^{-/-}$mice (Szumlinski et al., 2004), this mutant exhibits deficits several other forms of learning and memory, including simple habituation (Lominac et al., 2005; Szumlinski et al., 2005a), spatial learning/memory (Lominac et al., 2005; Szumlinski et al., 2005a; Jaubert et al., 2007), and instrumental learning (Szumlinski et al., 2005a; Wagner et al., 2014). Moreover, pan-Homer1 ${ }^{-/-}$mice are deficient in long-term depression (Ronesi and Huber, 2008) and long-term potentiation (Gerstein et al., 2012), while Homer1 $a^{-/-}$mice fail to exhibit homeostatic AMPA receptor scaling within cortex (Hu et al., 2010). In contrast to panHomer1 ${ }^{-/-}$mice (Szumlinski et al., 2005a), Homer1a-null mutants exhibited no observable deficits in the acquisition phase of a Morris water maze (Figure 2D), arguing that the induction of Homerla is not necessary for the consolidation 
or recall of the information pertaining to the platform location.

However, akin to pan-Homer $1^{-/-}$mice (Szumlinski et al., 2005a), both Homer1 $a^{+/-}$and Homer1a ${ }^{-/-}$animals spent less time in the quadrant of the pool that formerly contained the hidden platform on the probe test (Figure 2E). While this result might reflect impaired spatial memory recall, such an interpretation is inconsistent with their intact learning of the maze location during the acquisition phase of this experiment. As no genotypic differences were observed in the amount of floating behavior during Porsolt swim testing (Figure 1F) or in the total distance traveled during the probe trial (Figure 2E), it is unlikely that Homer1a deletion altered swimming capacity during the memory probe test. Alternatively, the reduced time spent in the platform quadrant might reflect the deployment of an alternative platform search or escape strategy in Homerla mutant mice. Indeed, pan-Homer $1^{-/-}$mice employ a "chaining" strategy to successfully navigate a water-version of the radial arm maze (Lominac et al., 2005; Szumlinski et al., 2005a) and AAV-mediated restoration of Homer1c, not Homerla, to the PFC of pan-Homer $1^{-/-}$mice reverse their deficits in spatial working memory (Lominac et al., 2005). Further, hippocampal restoration of Homer $1 \mathrm{c}$ reverses the spatial memory impairments exhibited by pan-Homer1 ${ }^{-/-}$(Gerstein et al., 2012), as well as aged mice (Gerstein et al., 2013) and hippocampal overexpression of Homerla impairs the acquisition and/or recall of spatial memories (Klugmann et al., 2005; Celikel et al., 2007). Thus, it is clear that a more concerted research effort is required to understand more precisely how Homerla induction within specific neurocircuits contributes to spatial and nonspatial learning of relevance to the etiology and treatment of attentional, learning and memory disorders (Wells et al., 2015).

\subsection{Preventing Homer1a Induction Profoundly Impairs in Vivo Regulation of NAC Neurotransmitter Levels}

Since their initial discovery, the glutamatergic consequences of Homer1 vs. Homerla deletion have been studied extensively in vitro, with a focus on the regulation of post-synaptic signal transduction mechanisms (cf. Shiraishi-Yamaguchi and Furuichi, 2007; Worley et al., 2007; Fagni, 2012; Marton et al., 2015). However, transfection of hippocampal neuronal cultures with constitutively expressed Homer isoforms can augment, while transfection with Homerla reduces, presynaptic neuronal activity (Sala et al., 2001) and a more recent study demonstrated opposing roles for CC- and IEG-Homer1 isoforms in regulating mGlu1/5-stimulated $\mathrm{Ca}^{2+}$ entry and glutamate release from astrocytes both in vitro and in situ (Buscemi et al., 2017). Further, CC- and IEG-Homer1 isoforms exert opposing effects upon mGlu1/5-dependent generation of anandamide (Jung et al., 2007), which is well-characterized to inhibit glutamate release via activation of CB1 receptors (e.g., Johnson and Lovinger, 2016). Indeed, we have reported several anomalies with respect to in vivo measures of glutamate function in the brains of pan-Homer1-/- mice, notably, reduced NAC and elevated
PFC basal extracellular glutamate content (Szumlinski et al., 2004, 2005a), and an altered capacity of acute cocaine to elevate extracellular glutamate levels within both the NAC (increased in pan-Homer $1^{-/-}$; Table 2) (Szumlinski et al., 2004) and PFC (decreased in pan-Homer ${ }^{-/-}$) (Lominac et al., 2005; Szumlinski et al., 2005a) that suggest a critical role for Homer1 proteins in regulating presynaptic aspects of glutamate transmission.

Herein, we report that, akin to Homer $2^{-/-}$mice (Szumlinski et al., 2004), pan-Homer $1^{-/-}$mice also exhibit a blunted capacity of the Group1 mGlu receptor agonist DHPG to stimulate glutamate release within the NAC (Figure 4B), which might reflect a "de-scaffolding" of mGlu1/5 receptors within neurons and/or astrocytes in this region (Brakeman et al., 1997; Tu et al., 1998, 1999; Buscemi et al., 2017). This being said, Homer1a-/mice also exhibited blunted DHPG-stimulated glutamate release (Figure 4A), as well as reduced basal extracellular glutamate content within the NAC (Figure 5B). These results were rather unexpected given that prior transgenic work argued a more critical role for CC-Homer1 versus Homerla expression in regulating extracellular glutamate levels in vivo (Lominac et al., 2005), as well as glutamate release in vitro (Buscemi et al., 2017) and Homer1a $a^{-/-}$mice exhibit increased cell surface expression of mGlu5 in situ and in vitro (Hu et al., 2010). While the source of the extracellular glutamate remains to be determined (i.e., neuronal, glial, or both), the capacity of DHPG to augment NAC glutamate levels in freely moving animals can be blocked by co-infusion of an mGlu1, but not mGlu5, inhibitor (Swanson et al., 2001). By extension then, the failure of both pan-Homer1-/- and Homer1a-/mice to exhibit a DHPG-induced rise in NAC extracellular glutamate likely relates to a deficit in mGlu1-dependent, rather than mGlu5-dependent, signaling, with the DHPG phenotype of pan-Homer $1^{-/-}$mice likely reflecting incapacity to induce Homerla.

DHPG-induced glutamate release within the NAC is also activity-dependent in vivo (Swanson et al., 2001). However, while Homer1 deletion does not alter the extraction fraction index of glutamate clearance/reuptake within the NAC (Szumlinski et al., 2005a), the extraction fraction was lower in Homer1a-/mice than wild-type controls (Figure 5C). This difference in extraction fraction was driven primarily by genotypic differences in glutamate flux at concentrations below $\mathrm{y}=0$ (Figure 5C), suggesting reduced glutamate release, rather than increased glutamate reuptake in Homer1a $a^{-/-}$animals (Parsons and Justice, 1992). Although Homer1a $a^{-/-}$mice do not exhibit changes in the frequency of miniature excitatory post-synaptic potentials within cortical pyramidal neurons ( $\mathrm{Hu}$ et al., 2010), Homer1a $a^{-/-}$mice exhibited robust deficits in high $\mathrm{K}^{+}$-stimulated release of both dopamine and glutamate within the NAC (Figures $\mathbf{4 C , E}$ ), which is a finding in-line with their blunted dopamine response to acute cocaine and their failure to exhibit both dopamine and glutamate sensitization with repeated cocaine treatment (Park et al., 2013; Figures 8A,B). In contrast, depolarization-induced glutamate or dopamine release was intact within the NAC of pan-Homer $1^{-/-}$mice, despite their lower extracellular glutamate levels (Figures 4D,F and Table 2). 
TABLE 2 | Comparison of the cocaine phenotype of Homer1a-/- versus pan-Homer1-/- mice.

\begin{tabular}{|c|c|c|c|}
\hline Paradigm & Dependent variable & Homer1a-/- & Pan-Homer1-/- \\
\hline \multicolumn{4}{|l|}{ Behavior: } \\
\hline \multirow[t]{2}{*}{ Activity monitoring } & Acute: total distance & $\mathrm{WT}<\mathrm{KO}^{4, \text { Section } 3.9 .2}$ & $\mathrm{WT}<\mathrm{KO}^{1}$ \\
\hline & Locomotor sensitization & $\mathrm{WT}>\mathrm{KO}^{4, \text { Section } 3.9 .2}$ & n.d. \\
\hline Conditioned place-preference & Time on paired side & $\mathrm{WT}=\mathrm{KO}$ Section 3.4,3.9.3 & WT ( KO1 \\
\hline \multicolumn{4}{|l|}{ Neurochemistry: } \\
\hline \multirow[t]{4}{*}{ Conventional microdialysis } & Acute cocaine: dopamine & $\mathrm{WT} \geq \mathrm{KO} \mathrm{O}^{4, \text { Section }} 3.10 .2$ & $\mathrm{WT}=\mathrm{KO}^{1}$ \\
\hline & Dopamine sensitization & $\mathrm{WT}>\mathrm{KO}^{4, \text { Section } 3.10 .2}$ & n.d. \\
\hline & Acute cocaine: glutamate & $\mathrm{WT}=\mathrm{KO}$, Section 3.10 .1 & $\mathrm{WT}<\mathrm{KO}^{1}$ \\
\hline & Glutamate sensitization & $\mathrm{WT}>\mathrm{KO}^{4, \text { Section } 3.10 .1}$ & n.d. \\
\hline
\end{tabular}

Summary of the results of comparable studies examining the effects of Homer1a or Homer1 deletion (KO) upon cocaine-induced changes in behavior and neurochemistry. $>$ Denotes greater response in wild-type (WT) than KO; < denotes less response in WT than KO; = denotes no genotypic difference; $\geq$ denotes inconsistencies in study outcomes, with reports of either no genotypic difference or greater response in WT than KO mice. Highlighted rows indicate phenotypic similarities between Homer1a-1and Homer1-1- mice. ${ }^{1}$ Szumlinski et al. (2004).

This result indicates that pan-Homer1 deletion does not grossly impair the excitability of either dopamine or glutamate terminals within this region - a finding consistent with the fact that cocaine can elevate the NAC levels of both neurotransmitters in Homer $1^{-/-}$mice (Szumlinski et al., 2004). Importantly, AAVmediated restoration of Homerla to the NAC of Homerla $a^{-/-}$ mice reversed both the anomalies in basal glutamate, as well as the blunted cocaine responsiveness of dopamine and glutamate observed in Homer1a $a^{-/}$animals, while NAC Homerla over-expression in Homer $1^{+/+}$mice was without any overt effect on our neurochemical measures (Figure 8). It remains to be determined whether or not virally mediated Homerla expression incorporates into the post-synaptic density in a manner akin to endogenous protein to influence neurotransmission. Nevertheless, the present neurochemical data argue that Homerla induction within the NAC actively regulates, but is not sufficient to augment, basal extracellular glutamate, as well as dopamine and glutamate responsiveness within this region. These data provide confirmatory evidence of a novel role for this IEG Homer1 isoform in regulating at least two neurotransmitters systems within a brain region highly implicated in incentive motivational and attentional processing.

\subsection{NAC Homer1a Induction Actively Regulates Cocaine-Induced Behavioral Sensitization But Not Conditioned Reward}

As reported previously (Park et al., 2013), the failure of Homer $1 a^{-/-}$mice to develop cocaine-induced neurochemical sensitization within the NAC (Figures 8A,B) is associated with a lack of locomotor sensitization in these animals (Figure 7C). Herein, we extend this prior work by demonstrating that AAV-mediated restoration of NAC Homerla reversed the sensitization phenotype of Homerla $a^{-/-}$mice, without significantly affecting spontaneous or cocaine-induced changes in locomotor activity within Homer1a $a^{+/+}$controls (Figure 7). While we previously observed no overt effects of Homerla deletion upon spontaneous locomotion or acute cocaine-induced locomotor-activity (Park et al., 2013), Homer1a-/- GFPcontrols exhibited blunted novelty-induced locomotion (Figure 7A), but greater locomotor activity in response to an acute cocaine injection (Figure 7B), which could relate to surgical/AAV procedures employed herein. Nevertheless, the striking parallels between the effects of manipulating Homerla induction upon behavioral and neurochemical sensitization within the NAC observed to date argue a facilitatory role for Homer1a induction in the development of dopamine/glutamate plasticity that sensitizes drug-induced psychomotor activity.

The capacity of cocaine to augment NAC Homerla expression (Brakeman et al., 1997; Ghasemzadeh et al., 2009b; Park et al., 2013) is reported to develop tolerance with repeated drug experience (Ghasemzadeh et al., 2009b). However, repeated cocaine exposure also reduces the NAC expression of constitutively expressed Homer1 and Homer2 proteins (e.g., Swanson et al., 2001; Ary and Szumlinski, 2007; Ben-Shahar et al., 2009; Ghasemzadeh et al., 2009a, 2011; Knackstedt et al., 2010; Loweth et al., 2014). A cocaine-induced reduction in the relative expression of CC-Homers is predicted to bias intracellular signaling within the NAC in favor of the dominant negative actions of the IEG isoforms, which we have now confirmed, herein, to be necessary for the development of drug-sensitized behavior. Consistent with this notion, pan-Homer1 deletion (Szumlinski et al., 2004; Lominac et al., 2005) or anti-sense oligonucleotide-mediated knock-down of Homer1 expression within the NAC augments the acute locomotor-stimulatory effects of cocaine (Ghasemzadeh et al., 2003). Conversely, restoration of the CC-Homer2b isoform to the NAC of cocaine Homer $2^{-/-}$mice (Szumlinski et al., 2004) or over-expression of either Homer1c or Homer2b within the NAC of cocainesensitized rats (Szumlinski et al., 2006) prevents their sensitized locomotor and glutamate responses to cocaine. Given the association between polymorphisms in the human Homer1 with disorders characterized by preservative behaviors (e.g., addiction, autism, and schizophrenia) (Norton et al., 2003; Dahl et al., 2005; Kelleher et al., 2012), it will be important to understand more precisely the mechanisms through which Homerla modulates the capacity of cocaine, as well as other 
TABLE 3 | Comparison of the NAC neurochemical phenotype of Homer1a-/- versus pan-Homer1-/- mice.

\begin{tabular}{|c|c|c|c|}
\hline Paradigm & Dependent variable & Homer1a-/- & Pan-Homer1-/- \\
\hline \multirow[t]{2}{*}{ Glutamate no net-flux } & x-intercept (basal glutamate) & $\mathrm{WT}>\mathrm{KO}$ Section 3.7,3.10.3 & $\mathrm{WT}>\mathrm{KO}^{1}$ \\
\hline & Slope (release/reuptake) & $\mathrm{WT} \geq \mathrm{KO}$ Section $3.7,3.10 .3$ & $\mathrm{WT}=\mathrm{KO}^{1}$ \\
\hline \multirow[t]{3}{*}{ Reverse dialysis } & DHPG-stimulated glutamate release & $\mathrm{WT}>\mathrm{KO}$ Section 3.5 & $\mathrm{WT}>\mathrm{KO}$ Section 3.5 \\
\hline & $\mathrm{K}^{+}$-stimulated glutamate release & $\mathrm{WT}>\mathrm{KO}$ Section 3.6 & $\mathrm{WT}=\mathrm{KO}$ Section 3.6 \\
\hline & K(-stimulated dopamine release & $\mathrm{WT}>\mathrm{KO}$ Section 3.6 & $\mathrm{WT}=\mathrm{KO}$ Section 3.6 \\
\hline
\end{tabular}

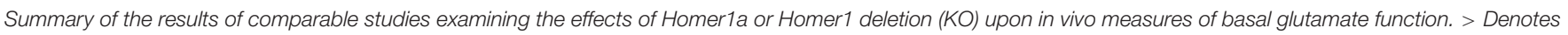

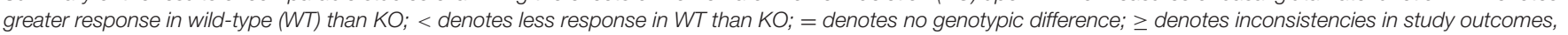

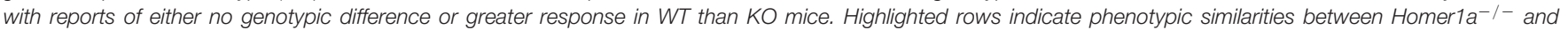
Homer1-/- mice. ${ }^{1}$ Szumlinski et al. (2005a); ${ }^{2}$ Szumlinski et al. (2004).

psychotomimetic drugs, to induce neuroplasticity within corticostriatal circuits that underpin enduring psychomotor hyperactivity.

Our prior studies of pan-Homer $1^{-/-}$and Homer $2^{-/-}$mice also demonstrated active and necessary roles for CC-Homer isoform expression within the NAC in regulating more complex forms of drug-induced associative and instrumental learning (Szumlinski et al., 2004, 2005b, 2008b; Lominac et al., 2005; Table 3). Indeed, disruption of Homer1-dependent binding within the NAC core subregion prevents both cue- and cocaineprimed reinstatement of drug-seeking (Wang et al., 2013), although AAV-mediated over-expression of either Homer1c or Homer2b within this subregion does not prevent the incubation of cue-elicited cocaine-seeking in rat models of drug selfadministration (Loweth et al., 2014). Given the robust effects of Homerla deletion upon cocaine-induced behavioral and neurochemical sensitization within the NAC, we were very surprised by the absolute lack of genotypic differences upon the capacity of cocaine to elicit a conditioned place-preference in mice (Figures 3, 7D). The cocaine doses and place-conditioning procedures employed in this study are sensitive to the effects of other transgenic manipulations of Homer and/or mGlu5 function (Szumlinski et al., 2004; Ary et al., 2013; Park et al., 2013). In fact, the dose-response function for cocaineinduced place-conditioning in both pan-Homer $1^{-/-}$, as well as Homer $2^{-/-}$, mice is shifted to the left of wild-type controls, indicating that deletion of either CC-Homer isoform increases behavioral sensitivity to cocaine-conditioned reward (Szumlinski et al., 2004). Important for data interpretation, the negative results for place-conditioning were derived from the same Homer $1 a^{+/+}$and Homer1a $a^{-/-}$that exhibit blunted cocaineinduced behavioral and neurochemical sensitization (AAV-naïve, Park et al., 2013; AAV-infused, Figures 7, 8) and thus, the disparate findings across the different dependent measures cannot reflect cohort effects.

Although both transgenic and pharmacological evidence indicates that a cocaine-conditioned place-preference can develop independent of a dopamine-sensitized state within the NAC (e.g., Szumlinski et al., 2004, 2007), in our experience and to the best of our knowledge, the Homer $1 a^{-/-}$mouse is the first example in which the magnitude of drug-conditioned reward in mice is independent of a glutamate-sensitized state within the NAC (e.g., Szumlinski et al., 2005a,b, 2008b, 2017; Penzner et al., 2008). Thus, while increasing NAC glutamate is sufficient to augment the magnitude of drug-induced place-conditioning (e.g., Szumlinski et al., 2017), NAC glutamate hypersensitivity does not appear to be required for this form of drug-related learning. Whether or not Homerla deletion impacts more complex drug-related instrumental learning remains to be determined.

The NAC receives major glutamate input from the PFC and local manipulations of both CC- and IEG-Homer expression can regulate extracellular glutamate, as well as the cocaine responsiveness of glutamate within the PFC (Lominac et al., 2005; Szumlinski et al., 2005a; Ary et al., 2013). In fact, mimicking cocaine-induced changes in the expression of different Homer isoforms within PFC (Ary and Szumlinski, 2007; Ben-Shahar et al., 2009; Gould et al., 2015), by increasing Homer2 expression or reducing Homer1c expression, produces a number of glutamatergic adaptations within the NAC of cocainenaïve mice that resemble those observed in cocaine-experience rodents (Ary et al., 2013). Importantly, mimicking the cocaineinduced imbalance in CC-Homer isoforms within PFC is also sufficient to potentiate a cocaine-conditioned place-preference (Ary et al., 2013). Conversely, Homer1c over-expression within ventral PFC prevents cocaine-primed reinstatement in a rat selfadministration model (Gould et al., 2015). As withdrawal from repeated cocaine augments the glutamate responsiveness to drugassociated cues (Shin et al., 2016) and prior work indicates that Homerla induction is required for normal homeostatic scaling of glutamatergic transmission within cortex (Hu et al., 2010), it will be important in future work to characterize the importance of Homerla induction for the gating of corticofugal glutamate output from PFC subregions and the executive control the PFC exerts over subcortical structures regulating incentive motivation, affect and learning. It is clear that Homerla function is complex, strengthening or weakening synaptic connectivity in manner that depends upon on-ongoing cellular activity and the specific intracellular signaling pathways engaged (e.g., Park et al., 2013; Marton et al., 2015). Given the interpretational difficulties associated with studying a constitutive mutant model, new animal models are required that are capable of acute upand down-regulation of this isoform within specific neuronal and glial populations, to gain a deeper understanding of how Homerla induction bi-directionally influences synaptic strength of relevance to the etiology of human neuropsychiatric disease. 


\section{AUTHOR CONTRIBUTIONS}

MCD, MW, CMR, KDL, and KKS conducted the experiments. MW, KL, and KKS analyzed the data. GvJ and MK supplied the AAVs. J-HH and PFW supplied the KO mice. MCD, PFW, and KKS composed the manuscript. All authors edited the manuscript.

\section{REFERENCES}

Ango, F., Pin, J. P., Tu, J. C., Xiao, B., Worley, P. F., Bockaert, J., et al. (2000). Dendritic and axonal targeting of type 5 metabotropic glutamate receptor is regulated by homer1 proteins and neuronal excitation. J. Neurosci. 20, 8710-8716.

Ango, F., Prézeau, L., Muller, T., Tu, J. C., Xiao, B., Worley, P. F., et al. (2001). Agonist-independent activation of metabotropic glutamate receptors by the intracellular protein Homer. Nature 411, 962-965. doi: 10.1038/3508 2096

Ary, A. W., Lominac, K. D., Wroten, M. G., Williams, A. R., Campbell, R. R., Ben-Shahar, O., et al. (2013). Imbalances in prefrontal cortex CC-Homer1 versus -Homer2 expression promote cocaine-seeking behavior. J. Neurosci. 33, 8101-8113. doi: 10.1523/JNEUROSCI.1727-12.2013

Ary, A. W., and Szumlinski, K. K. (2007). Regional differences in the effects of withdrawal from repeated cocaine upon Homer and glutamate receptor expression: a two-species comparison. Brain Res. 1184, 295-305. doi: 10.1016/j. brainres.2007.09.035

Banerjee, A., Luong, J. A., Ho, A., Saib, A. O., and Ploski, J. E. (2016). Overexpression of Homerla in the basal and lateral amygdala impairs fear conditioning and induces an autism-like social impairment. Mol. Autism 7, 16. doi: 10.1186/s13229-016-0077-9

Beneken, J., Tu, J. C., Xiao, B., Nuriya, M., Yuan, J. P., Worley, P. F., et al. (2000). Structure of the Homer EVH1 domain-peptide complex reveals a new twist in polyproline recognition. Neuron 26, 143-154. doi: 10.1016/S0896-6273(00) 81145-9

Ben-Shahar, O., Obara, I., Ary, A. W., Ma, N., Mangiardi, M. A., Medina, R. L., et al. (2009). Extended daily access to cocaine results in distinct alterations in Homer 1b/c and NMDA receptor subunit expression within the medial prefrontal cortex. Synapse 63, 598-609. doi: 10.1002/syn.20640

Berke, J. D., Paletzki, R. F., Aronson, G. J., Hyman, S. E., and Gerfen, C. R. (1998). A complex program of striatal gene expression induced by dopaminergic stimulation. J. Neurosci. 18, 5301-5310.

Bottai, D., Guzowski, J. F., Schwarz, M. K., Kang, S. H., Xiao, B., Lanahan, A., et al. (2002). Synaptic activity-induced conversion of intronic to exonic sequence in Homer 1 immediate early gene expression. J. Neurosci. 22, 167-175.

Brakeman, P. R., Lanahan, A. A., O’Brien, R., Roche, K., Barnes, C. A., Huganir, R. L., et al. (1997). Homer: a protein that selectively binds metabotropic glutamate receptors. Nature 386, 284-288. doi: 10.1038/386284a0

Buscemi, L., Ginet, V., Lopatar, J., Montana, V., Pucci, L., Spagnuolo, P., et al. (2017). Homer1 scaffold proteins govern $\mathrm{Ca}_{2}{ }^{+}$dynamics in normal and reactive astrocytes. Cereb. Cortex 27, 2365-2384. doi: 10.1093/cercor/ bhw078

Celikel, T., Marx, V., Freudenberg, F., Zivkovic, A., Resnik, E., Hasan, M. T., et al. (2007). Select overexpression of homerla in dorsal hippocampus impairs spatial working memory. Front. Neurosci. 1, 97-110. doi: 10.3389/neuro.01.1.1.007. 2007

Clark, K. R., Liu, X., McGrath, J. P., and Johnson, P. R. (1999). Highly purified recombinant adeno-associated virus vectors are biologically active and free of detectable helper and wild-type viruses. Hum. Gene Ther. 10, 1031-1039. doi: 10.1089/10430349950018427

Constantin, B. (2016). Role of scaffolding proteins in the regulation of TRPCdependent calcium entry. Adv. Exp. Med. Biol. 898, 379-403. doi: 10.1007/9783-319-26974-0_16

Cozzoli, D. K., Goulding, S. P., Zhang, P. W., Xiao, B., Hu, J.-H., Ary, A. W., et al. (2009). Binge drinking up-regulates accumbens mGluR5-Homer2-PI3K signaling: functional implications for alcoholism. J. Neurosci. 29, 8655-8668. doi: 10.1523/JNEUROSCI.5900-08.2009

\section{FUNDING}

This work was supported, in part, by a Young Investigator Award from Brain and Behavior Research Foundation (formerly NARSAD), and funds from the University of California, Santa Barbara to KKS, as well as NIDA grants DA 024038 to KKS and NIDA DA10309 to PFW.

Dahl, J. P., Kampman, K. M., Oslin, D. W., Weller, A. E., Lohoff, F. W., Ferraro, T. N., et al. (2005). Association of a polymorphism in the Homer1 gene with cocaine dependence in an African American population. Psychiatr. Genet. 15, 277-283. doi: 10.1097/00041444-200512000-00010

During, M. J., Young, D., Baer, K., Lawlor, P., and Klugmann, M. (2003). Development and optimization of adeno-associated virus vector transfer into the central nervous system. Methods Mol. Med. 76, 221-236.

Fagni, L. (2012). Diversity of metabotropic glutamate receptor-interacting proteins and pathophysiological functions. Adv. Exp. Med. Biol. 970, 63-79. doi: 10.1007/ 978-3-7091-0932-8_3

Gerstein, H., Lindstrom, M. J., and Burger, C. (2013). Gene delivery of Homer1c rescues spatial learning in a rodent model of cognitive aging. Neurobiol. Aging 34, 1963-1970. doi: 10.1016/j.neurobiolaging.2013.02.006

Gerstein, H., O’Riordan, K., Osting, S., Schwarz, M., and Burger, C. (2012). Rescue of synaptic plasticity and spatial learning deficits in the hippocampus of Homer1 knockout mice by recombinant Adeno-associated viral gene delivery of Homer1c. Neurobiol. Learn. Mem. 97, 17-29. doi: 10.1016/j.nlm.2011. 08.009

Ghasemzadeh, M. B., Permenter, L. K., Lake, R., Worley, P. F., and Kalivas, P. W. (2003). Homer 1 proteins and AMPA receptors modulate cocaine-induced behavioural plasticity. Eur. J. Neurosci. 18, 1645-1651. doi: 10.1046/j.14609568.2003.02880.x

Ghasemzadeh, M. B., Vasudevan, P., Giles, C., Purgianto, A., Seubert, C., and Mantsch, J. R. (2011). Glutamatergic plasticity in medial prefrontal cortex and ventral tegmental area following extended-access cocaine self-administration. Brain Res. 1413, 60-71. doi: 10.1016/j.brainres.2011.06.041

Ghasemzadeh, M. B., Vasudevan, P., Mueller, C. R., Seubert, C., and Mantsch, J. R. (2009a). Region-specific alterations in glutamate receptor expression and subcellular distribution following extinction of cocaine self-administration. Brain Res. 1267, 89-102.

Ghasemzadeh, M. B., Windham, L. K., Lake, R. W., Acker, C. J., and Kalivas, P. W. (2009b). Cocaine activates Homer1 immediate early gene transcription in the mesocorticolimbic circuit: differential regulation by dopamine and glutamate signaling. Synapse 63, 42-53. doi: 10.1002/syn.20577

Gould, A. T., Sacramento, A. D., Wroten, M. G., Miller, B. W., Klugmann, M., Ben-Shahar, O., et al. (2015). Extended access to intravenous cocaine imbalances ventromedial prefrontal cortex Homer1 versus Homer2 expression: implications for relapse. Addict. Biol. 20, 148-157. doi: 10.1111/adb.12088

Guo, W., Molinaro, G., Collins, K. A., Hays, S. A., Paylor, R., Worley, P. F., et al. (2016). Selective disruption of mGluR5-Homer interactions mimics multiple phenotypes of Fragile X Syndrome in mice. J. Neurosci. 36, 2131-2147. doi: 10.1523/JNEUROSCI.2921-15.2016

Hauck, B., Chen, L., and Xiao, W. (2003). Generation and characterization of chimeric recombinant AAV vectors. Mol. Ther. 7, 419-425. doi: 10.1016/S15250016(03)00012-1

Hayashi, M. K., Ames, H. M., and Hayashi, Y. (2006). Tetrameric hub structure of postsynaptic scaffolding protein homer. J. Neurosci. 26, 8492-8501. doi: 10.1523/JNEUROSCI.2731-06.2006

He, M., and Shippenberg, T. S. (2000). Strain differences in basal and cocaineevoked dopamine dynamics in mouse striatum. J. Pharmacol. Exp. Ther. 293, 121-127.

Hu, J.-H., Park, J. M., Park, S., Xiao, B., Dehoff, M. H., Kim, S., et al. (2010). Homeostatic scaling requires group I mGluR activation mediated by Homerla. Neuron 68, 1128-1142. doi: 10.1016/j.neuron.2010.11.008

Inoue, N., Nakao, H., Migishima, R., Hino, T., Matsui, M., Hayashi, F., et al. (2009). Requirement of the immediate early gene vesl-1S/homer-1a for fear memory formation. Mol. Brain 2:7. doi: 10.1186/1756-6606-2-7 
Jaubert, P. J., Golub, M. S., Lo, Y. Y., Germann, S. L., Dehoff, M. H., Worley, P. F., et al. (2007). Complex, multimodal behavioral profile of the Homer1 knockout mouse. Genes Brain Behav. 6, 141-154. doi: 10.1111/j.1601-183X.2006.00240.x

Johnson, K. A., and Lovinger, D. M. (2016). Presynaptic G protein-coupled receptors: gatekeepers of addiction? Front. Cell. Neurosci. 10:264. doi: 10.3389/ fncel.2016.00264

Jung, K. M., Astarita, G., Zhu, C., Wallace, M., Mackie, K., and Piomelli, D. (2007). A key role for diacylglycerol lipase-alpha in metabotropic glutamate receptor dependent endocannabinoid mobilization. Mol. Pharmacol. 72, 612-621. doi: 10.1124/mol.107.037796

Kato, A., Ozawa, F., Saitoh, Y., Fukazawa, Y., Sugiyama, H., and Inokuchi, K. (1998). Novel members of the Vesl/Homer family of PDZ proteins that bind metabotropic glutamate receptors. J. Biol. Chem. 273, 23969-23975. doi: $10.1074 / j b c .273 .37 .23969$

Kelleher, R. J. III, Geigenmuller, U., Hovhannisyan, H., Trautman, E., Pinard, R., Rathmell, B., et al. (2012). High-throughput sequencing of mGluR signaling pathway genes reveals enrichment of rare variants in autism. PLOS ONE 7:e35003. doi: 10.1371/journal.pone.0035003

Klugmann, M., Symes, C. W., Leichtlein, C. B., Klaussner, B. K., Dunning, J., Fong, D., et al. (2005). AAV-mediated hippocampal expression of short and long Homer 1 proteins differentially affect cognition and seizure activity in adult rats. Mol. Cell. Neurosci. 28, 347-360. doi: 10.1016/j.mcn.2004.10.002

Klugmann, M., and Szumlinski, K. K. (2008). Targeting Homer genes using AAV: lessons learned from behavioural and neurochemical studies. Behav. Pharmacol. 19, 485-500. doi: 10.1097/FBP.0b013e32830c369f

Knackstedt, L. A., Moussawi, K., Lalumiere, R., Schwendt, M., Klugmann, M., and Kalivas, P. W. (2010). Extinction training after cocaine self-administration induces glutamatergic plasticity to inhibit cocaine seeking. J. Neurosci. 30, 7984-7992. doi: 10.1523/JNEUROSCI.1244-10.2010

Lee, K. M., Coehlo, M., McGregor, H. A., Waltermire, R. S., and Szumlinski, K. K. (2015). Binge alcohol drinking elicits persistent negative affect in mice. Behav. Brain Res. 291, 385-398. doi: 10.1016/j.bbr.2015.05.055

Lominac, K. D., McKenna, C. L., Schwartz, L. M., Ruiz, P. N., Wroten, M. G., Miller, B. W., et al. (2014). Mesocorticolimbic monoamine correlates of methamphetamine sensitization and motivation. Front. Syst. Neurosci. 8:70. doi: $10.3389 /$ fnsys.2014.00070

Lominac, K. D., Oleson, E. B., Pava, M., Klugmann, M., Schwarz, M. K., Seeburg, P. H., et al. (2005). Distinct roles for different Homer1 isoforms in behaviors and associated prefrontal cortex function. J. Neurosci. 25, 11586-11594. doi: 10.1523/JNEUROSCI.3764-05.2005

Lominac, K. D., Sacramento, A. D., Szumlinski, K. K., and Kippin, T. E. (2012). Distinct neurochemical adaptations within the nucleus accumbens produced by a history of self-administered versus non-contingently administered intravenous methamphetamine. Neuropsychopharmacology 37, 707-722. doi: 10.1038/npp.2011.248

Loweth, J. A., Scheyer, A. F., Milovanovic, M., Lacrosse, A. L., Flores-Barrera, E., Werner, C. T., et al. (2014). Synaptic depression via mGluR1 positive allosteric modulation suppresses cue-induced cocaine craving. Nat. Neurosci. 17, 73-80. doi: $10.1038 / \mathrm{nn} .3590$

Marton, T. M., Hussain Shuler, M. G., and Worley, P. F. (2015). Homerla and mGluR5 phosphorylation in reward-sensitive metaplasticity: a hypothesis of neuronal selection and bidirectional synaptic plasticity. Brain Res. 1628, 17-28. doi: 10.1016/j.brainres.2015.06.037

Morein-Zamir, S., and Robbins, T. W. (2015). Fronto-striatal circuits in responseinhibition: relevance to addiction. Brain Res. 1628, 117-129. doi: 10.1016/j. brainres.2014.09.012

Norton, N., Williams, H. J., Williams, N. M., Spurlock, G., Zammit, S., Jones, G., et al. (2003). Mutation screening of the Homer gene family and association analysis in schizophrenia. Am. J. Med. Genet. B Neuropsychiatr. Genet. 120B, 18-21. doi: 10.1002/ajmg.b.20032

Park, J. M., Hu, J. H., Milshteyn, A., Zhang, P. W., Moore, C. G., Park, S., et al. (2013). A prolyl-isomerase mediates dopamine-dependent plasticity and cocaine motor sensitization. Cell 154, 637-650. doi: 10.1016/j.cell.2013.07.001

Parsons, L. H., and Justice, J. B. Jr. (1992). Extracellular concentration and in vivo recovery of dopamine in the nucleus accumbens using microdialysis. J. Neurochem. 58, 212-218. doi: 10.1111/j.1471-4159.1992.tb09298.x

Paxinos, G., and Franklin, K. (2013). The Mouse Brain in Stereotaxic Coordinates, 4th Edn. Cambridge, MA: Academic Press.
Penzner, J. H., Thompson, D. L., Arth, C., Fowler, J. K., Ary, A. W., and Szumlinski, K. K. (2008). Protracted "anti-addictive" phenotype produced in C57BL/6J mice by adolescent phenylpropanolamine treatment. Addict. Biol. 13, 310-325. doi: 10.1111/j.1369-1600.2008.00101.x

Rao, S., Leung, C. S., Lam, M. H., Wing, Y. K., Waye, M. M., and Tsui, S. K. (2017). Resequencing three candidate genes discovers seven potentially deleterious variants susceptibility to major depressive disorder and suicide attempts in Chinese. Gene 603, 34-41. doi: 10.1016/j.gene.2016.12.006

Rietschel, M., Mattheisen, M., Frank, J., Treutlein, J., Degenhardt, F., Breuer, R., et al. (2010). Genome-wide association-, replication-, and neuroimaging study implicates HOMER1 in the etiology of major depression. Biol. Psychiatry 68, 578-585. doi: 10.1016/j.biopsych.2010.05.038

Ronesi, J. A., and Huber, K. M. (2008). Homer interactions are necessary for metabotropic glutamate receptor-induced long-term depression and translational activation. J. Neurosci. 28, 543-547. doi: 10.1523/JNEUROSCI. 5019-07.2008

Sala, C., Piech, V., Wilson, N. R., Passafaro, M., Liu, G., and Sheng, M. (2001). Regulation of dendritic spine morphology and synaptic function by Shank and Homer. Neuron 31, 115-130. doi: 10.1016/S0896-6273(01)00339-7

Scofield, M. D., Heinsbroek, J. A., Gipson, C. D., Kupchik, Y. M., Spencer, S., Smith, A. C., et al. (2016). The nucleus accumbens: mechanisms of addiction across drug classes reflect the importance of glutamate homeostasis. Pharmacol. Rev. 68, 816-871. doi: 10.1124/pr.116.012484

Shin, C. B., Serchia, M., Shahin, J., Ruppert-Mejor, M., and Szumlinski, K. K. (2016). Incubation of cue-elicited glutamate release within prefrontal cortex. Neuropharmacology 102, 103-110. doi: 10.1016/j.neuropharm.2015.10.038

Shiraishi-Yamaguchi, Y., and Furuichi, T. (2007). The Homer family proteins. Genome Biol. 8, 206. doi: 10.1186/gb-2007-8-2-206

Soloviev, M. M., Ciruela, F., Chan, W. Y., and McIlhinney, R. A. (2000). Mouse brain and muscle tissues constitutively express high levels of Homer proteins. Eur. J. Biochem. 267, 634-639. doi: 10.1046/j.1432-1327.2000.01078.x

Strauss, J., McGregor, S., Freeman, N., Tiwari, A., George, C. J., Kovacs, M., et al. (2012). Association study of early-immediate genes in childhood-onset mood disorders and suicide attempt. Psychiatry Res. 197, 49-54. doi: 10.1016/j. psychres.2011.11.022

Swanson, C. J., Baker, D. A., Carson, D., Worley, P. F., and Kalivas, P. W. (2001). Repeated cocaine administration attenuates group I metabotropic glutamate receptor-mediated glutamate release and behavioral activation: a potential role for Homer. J. Neurosci. 21, 9043-9052.

Szumlinski, K. K., Abernathy, K. E., Oleson, E. B., Klugmann, M., Lominac, K. D., He, D.-Y., et al. (2006). Homer isoforms differentially regulate cocaine-induced neuroplasticity. Neuropsychopharmacology 31, 768-777. doi: 10.1038/sj.npp. 1300890

Szumlinski, K. K., Ary, A. W., and Lominac, K. D. (2008a). Homers regulate druginduced neuroplasticity: implications for addiction. Biochem. Pharmacol. 75, 112-133.

Szumlinski, K. K., Ary, A. W., Lominac, K. D., Klugmann, M., and Kippin, T. E. (2008b). Accumbens Homer2 over-expression facilitates alcoholinduced neuroplasticity in C57BL/6J mice. Neuropsychopharmacology 33, $1365-1378$.

Szumlinski, K. K., Dehoff, M. H., Kang, S. H., Frys, K. A., Lominac, K. D., Rohrer, J., et al. (2004). Homer proteins regulate vulnerability to cocaine. Neuron 43, 401-413. doi: 10.1523/JNEUROSCI.1727-12.2013

Szumlinski, K. K., Liu, A., Penzner, J. H., and Lominac, K. D. (2007). Protracted "pro-addictive" phenotype produced by pre-adolescent phenylpropanolamine. Neuropsychopharmacology $32, \quad 1760-1773 . \quad$ doi: $10.1038 /$ sj.npp. 1301306

Szumlinski, K. K., Lominac, K. D., Campbell, R. R., Cohen, M., Fultz, E. K., Brown, C. N., et al. (2017). Methamphetamine addiction vulnerability: the glutamate, the bad and the ugly. Biol. Psychiatry 81, 959-970. doi: 10.1016/j.biopsych.2016. 10.005

Szumlinski, K. K., Lominac, K. D., Kleschen, M., Oleson, E. B., Dehoff, M., Schwarz, M., et al. (2005a). Behavioural and neurochemical phenotyping of Homer1 mutant mice: possible implications for schizophrenia. Genes Brain Behav. 4, 273-288.

Szumlinski, K. K., Lominac, K. D., Oleson, E. B., Walker, J. K., Mason, A., Dehoff, M. H., et al. (2005b). Homer2 is necessary for ethanol-induced neuroplasticity. J. Neurosci. 25, 7054-7061. 
Tappe, A., and Kuner, R. (2006). Regulation of motor performance and striatal function by synaptic scaffolding proteins of the Homerl family. Proc. Natl. Acad. Sci. U.S.A. 103, 774-779. doi: 10.1073/pnas.05059 00103

Tu, J. C., Xiao, B., Naisbitt, S., Yuan, J. P., Petralia, R. S., Brakeman, P., et al. (1999). Coupling of mGluR/Homer and PSD-95 complexes by the Shank family of postsynaptic density proteins. Neuron 23, 583-592. doi: 10.1016/S08966273(00)80810-7

Tu, J. C., Xiao, B., Yuan, J. P., Lanahan, A. A., Leoffert, K., Li, M., et al. (1998). Homer binds a novel proline-rich motif and links group 1 metabotropic glutamate receptors with IP3 receptors. Neuron 21, 717-726. doi: 10.1016/ S0896-6273(00)80589-9

Vazdarjanova, A., McNaughton, B. L., Barnes, C. A., Worley, P. F., and Guzowski, J. F. (2002). Experience-dependent coincident expression of the effector immediate-early genes arc and Homer la in hippocampal and neocortical neuronal networks. J. Neurosci. 22, 10067-10071.

Wagner, K. V., Hartmann, J., Labermaier, C., Häusl, A. S., Zhao, G., Harbich, D., et al. (2015). Homer1/mGluR5 activity moderates vulnerability to chronic social stress. Neuropsychopharmacology 40, 1222-1233. doi: 10.1038/npp. 2014.308

Wagner, K. V., Hartmann, J., Mangold, K., Wang, X. D., Labermaier, C., Liebl, C., et al. (2013). Homerl mediates acute stress-induced cognitive deficits in the dorsal hippocampus. J. Neurosci. 33, 3857-3864. doi: 10.1523/JNEUROSCI. 4333-12.2013

Wagner, K. V., Häusl, A. S., Pöhlmann, M. L., Hartmann, J., Labermaier, C., Müller, M. B., et al. (2014). Hippocampal Homer1 levels influence motivational behavior in an operant conditioning task. PLOS ONE 9:e85975. doi: 10.1371/ journal.pone.0085975
Wang, X., Moussawi, K., Knackstedt, L., Shen, H., and Kalivas, P. W. (2013). Role of mGluR5 neurotransmission in reinstated cocaine-seeking. Addict. Biol. 18, 40-49. doi: 10.1111/j.1369-1600.2011.00432.x

Wells, T. T., Judah, M. R., Ellis, A. J., McGeary, J. E., and Beevers, C. G. (2015). Inhibition of attention for affective material: contributions by HOMER1 gene variation. Psychol. Neurosci. 8, 495-508. doi: 10.1037/pne000 0027

Worley, P. F., Zeng, W., Huang, G., Kim, J. Y., Shin, D. M., Kim, M. S., et al. (2007). Homer proteins in $\mathrm{Ca}^{2+}$ signaling by excitable and non-excitable cells. Cell Calcium 42, 363-371. doi: 10.1016/j.ceca.2007.05.007

Xiao, B., Tu, J. C., Petralia, R. S., Yuan, J. P., Doan, A., Breder, C. D., et al. (1998). Homer regulates the association of group 1 metabotropic glutamate receptors with multivalent complexes of homer-related, synaptic proteins. Neuron 21, 707-716. doi: 10.1016/S0896-6273(00)80588-7

Yuan, J. P., Kiselyov, K., Shin, D. M., Chen, J., Shcheynikov, N., Kang, S. H., et al. (2003). Homer binds TRPC family channels and is required for gating of TRPC1 by IP3 receptors. Cell 114, 777-789. doi: 10.1016/S0092-8674(03)00716-5

Conflict of Interest Statement: The authors declare that the research was conducted in the absence of any commercial or financial relationships that could be construed as a potential conflict of interest.

Copyright (c) 2017 Datko, Hu, Williams, Reyes, Lominac, von Jonquieres, Klugmann, Worley and Szumlinski. This is an open-access article distributed under the terms of the Creative Commons Attribution License (CC BY). The use, distribution or reproduction in other forums is permitted, provided the original author(s) or licensor are credited and that the original publication in this journal is cited, in accordance with accepted academic practice. No use, distribution or reproduction is permitted which does not comply with these terms. 